\title{
Ultimate behavior of idealized composite floor elements at ambient and elevated temperature
}

\author{
K.A. Cashell, A.Y. Elghazouli* and B.A. Izzuddin \\ Department of Civil and Environmental Engineering, Imperial College London, \\ $U K$
}

\begin{abstract}
This paper is concerned with the ultimate behavior of composite floor slabs under extreme loading situations resembling those occurring during severe building fires. The study focuses on the failure state associated with rupture of the reinforcement in idealized slab elements, which become lightly reinforced in a fire situation due to the early loss of the steel deck. The paper describes a fundamental approach for assessing the failure limit associated with reinforcement fracture in lightly reinforced beams, representing idealized slab strips. A description of the ambienttemperature tests on isolated restrained elements, carried out to assess the influence of key material parameters on the failure conditions, is firstly presented. The results of a series of material tests, undertaken mainly to examine the effect of elevated temperature on ductility, are also described. A simplified analytical model is employed, in conjunction with the experimental findings, to assess the salient material parameters and their implications on the ultimate response at both ambient and elevated temperature.
\end{abstract}

Keywords: structural fire behavior, composite floors, slab strips, failure conditions

* Corresponding author

Telephone: 0044-2075946021; Email: a.elghazouli@imperial.ac.uk 


\section{Introduction}

The structural fire performance of buildings with composite steel-concrete floors has been the subject of extensive research investigations in recent years, e.g. [1-7]. These studies have identified the crucial role played by the composite floor slab in carrying the gravity loading within the fire compartment, after the supporting steel beams have lost their strength due to elevated temperature. Verification of this behavior was established during large-scale fire tests carried out in the UK $[1,3,8]$. Although the slab exhibits significantly lower bending capacity, the development of tensile catenary action coupled with several sources of over-design leads to considerable fire resistance capabilities. To this end, progress in the development of improved design approaches needs to be based on detailed assessment of the behavior of floor slabs, using reliable and realistic modeling approaches coupled with the application of appropriate failure criteria.

A typical composite slab, of the form shown in Fig. 1, is normally supported by steel beams acting compositely with the slab through shear connectors. The conventional design procedure is to treat the short direction of the slab, as well as the secondary and primary beams, as a one-dimensional member supporting the load from the floor. Depending on the extent of fire spread within compartments and the degree of fire protection that has been applied, some of the structural elements such as steel beams and the steel deck can develop high temperatures and become largely ineffective at an early stage. As a result, the slab behaves primarily as a concrete element with light mesh reinforcement, which is required to span over the ineffective steel beams and hence sustain the gravity load from a larger floor area than that intended by design.

Although the flexural capacity of the slab is significantly reduced due to the loss of the steel deck, it is still able to provide considerable fire resistance. This is contributed to by several aspects of floor over-design, caused by the idealization of the member behavior and support conditions. Most importantly, the slab is usually able to develop tensile catenary action, which significantly increases the load-carrying capacity. The existence of considerable planar restraint in most situations has been discussed and illustrated in earlier studies, e.g. [3-6]. In an internal compartment, this is effectively provided by the surrounding cooler structure. On the other hand, in edge compartments, the perimeter beams retain 
significant stiffness due to their relatively lower temperatures. Besides, the development of a compressive ring in the slab with the presence of adequate reinforcement anchorage contributes to the provision of a degree of planar restraint.

The form of the load-deflection response for lightly reinforced concrete beams is heavily dependant on the restraint conditions present. For a onedimensional strip with sufficient axial restraint, at low deflections the conventional bending behavior is enhanced by compressive arching. Following the attainment of maximum load, the load reduces progressively as the slab deforms until tensile catenary action begins to develop at displacement level exceeding the slab depth [9]. From this point onwards, the steel reinforcement starts to act as a tensile catenary, or tensile membrane, and supports the load until failure occurs. Consequently, one of the most important failure criteria for composite slabs is that related to rupture of the reinforcement. Prediction of the displacement and load levels corresponding to this type of failure is, however, a complex issue that necessitates a detailed treatment of the interaction between the concrete material and steel reinforcement, with due account of the appropriate loading and boundary conditions. As there are several uncertainties related to the key material and response parameters, this issue also requires experimental validation and calibration.

This paper describes the first phase of an experimental study focusing on the ultimate behavior of strip and slab behavior. These tests have been undertaken in order to gain an insight into the underlying mechanisms governing behavior, with a view to improving structural fire design approaches. A full account of the beam and slab tests can be found elsewhere [10]. A description is given of the results from selected tests on isolated reinforced concrete beams representing idealized slab strips. In addition, a comparative assessment of bond properties is carried out through conventional pullout tests. Due to the dearth of specific information relating to the ultimate behavior of steel reinforcement at elevated temperatures, an experimental investigation was undertaken to determine these effects. Key results from these material tests are presented in the paper and compared with information available in design guides. Finally, analytical models developed to represent the behavior of isolated lightly reinforced beams are described, and utilized to highlight the influence of key material properties on the 
response. The work described in this paper represents a fundamental step towards characterizing the ultimate behavior of composite floors under fire conditions. Subsequent stages of the experimental and numerical investigation are currently underway [10].

\section{Idealized member tests}

A number of ambient tests have been carried out in order to gain a greater understanding of the ultimate behavior of reinforced concrete members representing composite slab strips under simulated fire conditions. Although the ultimate application of this study is structural fire design, the ambient tests and associated analytical investigations are an essential precursor to the formulation of an adequate model for the failure of floor slabs under fire. A primary objective was to provide the necessary fundamental information to validate and calibrate the appropriate failure criteria. Selected tests from this experimental investigation are presented in this section, mainly in order to highlight the influence of reinforcement characteristics on the ultimate response.

\subsection{Material properties}

Both plain and ribbed reinforcing bars have been considered in the experimental investigation, in order to provide a range of characteristics and assess their influence on the overall response. Several tensile tests were conducted for each bar type using carefully-selected measuring equipment which was capable of capturing the full stress-strain behavior. The average yield and ultimate strengths exhibited by the reinforcement, $f_{y}$ and $f_{u l t}$, were $250 \mathrm{~N} / \mathrm{mm}^{2}$ and $330 \mathrm{~N} / \mathrm{mm}^{2}$ for the plain bars and $585 \mathrm{~N} / \mathrm{mm}^{2}$ and $625 \mathrm{~N} / \mathrm{mm}^{2}$ for the ribbed reinforcement. The corresponding ultimate strains $\left(\varepsilon_{u l t}\right)$ were 0.2 and 0.04 for the plain and ribbed bars, respectively. Both reinforcement-types had a diameter of $6 \mathrm{~mm}$ and the designations used for each are P6 and D6 for the plain and deformed bars. The P6 bars were hot-rolled and therefore $f_{y}$ was easily distinguishable from the response. In contrast, the D6 reinforcement was cold-worked and therefore displayed a more continuous stress-strain relationship; accordingly the yield strength for these bars was defined as the stress corresponding to a permanent strain of $0.2 \%$. An average compressive concrete strength of $40 \mathrm{~N} / \mathrm{mm}^{2}$ was utilized in all experiments. 
The bond between the reinforcement bars and concrete plays a key role in determining the failure limit of the members. There are several techniques used for bond testing, with the most common being the pull-out and beam approaches. In selecting the most appropriate test method, consideration should be given to the actual conditions prevailing in the member. Whereas replicating the real bond conditions in a structural member through simple testing techniques is difficult, it was decided to perform pullout tests to obtain a qualitative assessment of bond for different bars. The pullout tests can also provide an effective means of examining the comparative influence of other parameters on bond strength.

The influence of a number of factors such as the type of reinforcement, the bond-slip length and also the concrete cover was examined through the pullout tests. As expected, the type of reinforcement had a direct influence on the development of bond strength. This is illustrated in the example of bond-slip response shown in Fig. 2 for plain (P6) and deformed (D6) bars of the same diameter. The bond strength in plain bars is primarily due to adhesion and friction whereas these are compounded by mechanical interlocking when the bar is ribbed. This is illustrated in Fig. 2 where, as expected, it is shown that the bond strength developed by the deformed bar is much greater than that for the plain equivalent. The shape of the bond-slip relationship also differs due to the different mechanisms involved in the behavior.

The bond embedment length and concrete cover to the reinforcement also have a direct effect on the bond-slip characteristics. For example, Fig. 3 shows the response obtained from two pull-out tests employing $p$ bars, which have different embedment lengths. L1 and L2 correspond to multiples of 5 and 10 times the bar diameter, respectively. Clearly, the shorter bonded length generates greater bond stress along the length, but the residual stress is similar in both cases, as expected. On the other hand, the effect of concrete cover is illustrated in Fig. 4 where C1 corresponds to a cover of $75 \mathrm{~mm}$ whereas $\mathrm{C} 2$ has $20 \mathrm{~mm}$ cover. In this case, pullout failure occurred in both tests but in some situations, especially if deformed bars are used, splitting failure can occur. Whilst in pull-out behavior, some residual bond strength is normally present, in the case of splitting failure the residual bond diminishes with increasing values of slip. 


\subsection{Beam response}

In order to examine the ultimate behavior of idealized members representing isolated strips of slabs, the experimental set-up illustrated schematically in Fig. 5 was considered. The specimens were free to move rotationally whereas in terms of axial restraint, the set-up could be adjusted to simulate either pull-in only, push-out only, or both. Loading was applied at the middle of the specimen through closely spaced points to simulate concentrated mid-span loading. A single-point load was initially adopted but the wide crack typically occurring at mid-length interfered with the loading system. It was hence decided to replace this with two closely-spaced loading points at mid-length. A hydraulic actuator was used which operated in displacement control. In each test, the displacement was increased gradually until failure was reached by fracture of the reinforcement, which was typically accompanied by a significant reduction in the load carrying capacity.

The testing programme included specimens with various reinforcement configurations, bar-types and boundary conditions. This paper focuses on the results from six beam elements which were restrained from pulling-in, hence able to develop tensile catenary action. As noted before, the primary aim of the tests was to examine the influence of different reinforcement properties in the ultimate behavior, and to provide a more realistic assessment of the prevalent bond characteristics. The analytical models will also be calibrated based on the results. The key geometrical details for each of the selected tests are described in Table 1 where it is shown that the reinforcement ratio $(\rho)$ was varied from approximately $0.2 \%$ to $1.2 \%$, and both plain and deformed reinforcement bars were employed. The depth given in the table is the overall member depth and the reinforcement was placed at the mid-depth of each cross-section. A large amount of data was obtained through the measurements of displacements, loads and strains during the experiments. However, emphasis is placed herein on the total applied load $\left(F_{f, t e s t}\right)$ and the vertical deformation $\left(U_{f, t e s t}\right)$ at failure, which are also given in Table 1 for each test. These values correspond to the point at which fracture of the reinforcement occurred. Table 1 also indicates the number of cracks present at failure for each test as this has a direct influence on member ductility, as discussed in subsequent sections. The overall load-displacement response 
obtained for the specimens with plain and deformed bars are given in Figs. 6 and 7.

Fig. 6 illustrates the response of three members utilizing identical plain bars but with varying reinforcement ratios of $0.23 \%, 0.52 \%$ and $1.18 \%$ for strips $\mathrm{S} 1, \mathrm{~S} 2$ and S3, respectively. It is recalled that these bars had a relatively high ultimate strain of approximately $20 \%$. As shown in the figure, the behavior was quite ductile as a result of the combination of the reinforcement ductility together with the relatively low bond stress exhibited by the plain bars. Moreover, as shown in Table 1, another implication of the relatively low bond strength was that only a single crack formed in each member, irrespective of the reinforcement ratio. Consequently, the failure displacements were almost identical for all three specimens. Despite the relatively low yield capacity of the three specimens, the ability to develop considerable membrane action resulted in a much-enhanced overall load-carrying capacity.

The overall response from the three specimens reinforced with deformed bars is illustrated in Fig. 7. As noted before, the reinforcement ratios were $0.23 \%$, $0.52 \%$ and $1.18 \%$ for S4-S6, respectively. In contrast to the plain bars, these bars had a relatively low ultimate strain of about $4 \%$. Although the beams were axially restrained from pulling in, it is evident from Fig. 7 that these specimens failed before the effective development of tensile catenary action. This was due to the low ductility of the reinforcement combined with comparatively high bond strength. The increased bond strength leads to a greater degree of strain concentration in the steel and consequently failure is expedited.

This is, however, counterbalanced to some extent by multiple cracking particularly for higher reinforcement ratios, as indicated in Table 1 and Fig. 7. It is evident that in each of the specimens reinforced with deformed bars, the combination of bond strength and a higher reinforcement ratio results in a greater degree of cracking. This, in turn, increases the ductility of the member and ultimately delays failure. Clearly, the assumption of a single crack would be more realistic for lightly reinforced elements with a relatively low reinforcement ratio, characteristic of that typically used in composite slabs. However, for members with a higher reinforcement ratio, the assumption of a single crack would evidently provide a conservative prediction of failure displacement. It is important to note that, despite the higher yield strength of the deformed bars compared to 
the plain bars, members with the same reinforcement ratio have a lower capacity in the case of deformed bars. This can be observed by comparing the total failure loads $\left(F_{f, t e s t}\right)$ of S1-S3 with those of S4-S6 in Table 1. This is a consequence of the more pronounced strain concentration that occurs in members with deformed bars (as a result of the higher bond strength), which leads to relatively lower ability to carry loads through tensile catenary action.

\section{Simplified failure model}

As discussed before, a key mode of failure for lightly-reinforced members, both at ambient and elevated temperature, is fracture of the reinforcement across a localized through-depth crack. This localization is primarily due to the light reinforcement being unable to cause significant cracking, resulting in high concentrations of strain in the steel. In order to account for this failure criterion, it is important to determine the levels of deformation that can safely be sustained by the member. A conventional smeared crack approach, as employed by many researchers, provides good representation of the load-deflection response but cannot assess reliably the strain concentrations across the cracks. The concentrations depicted using these methods are unrealistically dependent on the element size instead of the geometric and material characteristics of the member. Accordingly, a more fundamental approach is necessary.

\subsection{Analytical representation}

An analytical model for representing the behavior of restrained lightly reinforced concrete members both at ambient and elevated temperature has been recently proposed at Imperial College $[9,11]$. Importantly, this approach includes a provision for predicting when the reinforcement will fracture, resulting in failure. The model represents the post-cracking behavior of an axially restrained member subject to mid-span loading, as shown in Fig. 8. A single layer of reinforcement is located at a prescribed depth, $h_{c}$, and the centre of rotation is user-defined but can, for simplicity, be assumed to be at the top concrete fiber. Depending on the combination of loading, geometry and material properties, the half-length $L$ consists of two regions, namely the 'bond-slip' and the 'no bondslip', as indicated in Fig. 8. The length of the 'bond-slip' region extends towards the support as the beam deflects. By incorporating the full stress-strain 
relationship for the steel reinforcement and appropriate properties for concrete, as well as bond-slip between the steel and concrete, the load-displacement response of the member can be determined. Most importantly, the deformation and load levels corresponding to the attainment of ultimate strain in the steel can be obtained, hence providing a prediction of the failure limit associated with reinforcement fracture. At elevated temperature, the approach accounts for the degradation of material properties - including those of steel, concrete and bondand also considers the effects of thermal expansion and thermal curvature

The full analytical model can be readily modified for any boundary or loading conditions. A more simplified version focuses on the tensile catenary response only and, for simplicity, this version is adopted herein. It can predict the failure displacement in all cases [11], but only represents the failure load if reinforcement fracture occurs in the tensile catenary stage. It is also assumed that the reinforcement is light enough to cause only a single crack at mid-span. This has been shown to be a conservative assumption [9] as discussed before. The bond stress-slip behavior is idealized as a rigid-plastic relationship and the stresses in the concrete are assumed to remain within its compressive strength.

The full set of formulations employed by the model is given elsewhere [9]. The model procedure is to incrementally apply an axial force to the steel at the crack face and subsequently: (i) calculate the resulting generalized axial and curvature strains in the two regions, i.e. the areas with and without bond-slip, (ii) establish the length of the bond-slip region, (iii) calculate the total extension of the steel based on the total strain in the bond-slip region as well as that in the no-slip region and (iv) apply compatibility to determine the deflection and load for that applied stress. The amount by which the reinforcement extends is dependant on the material characteristics, including bond strength, together with the axial force in the bars. Considering the compatibility diagram for the half-beam of length $L$ shown in Fig. 9, the beam deflection, $U$, and half of the applied load, $P$, are given by Eq.s (1) and (2):

$$
\begin{aligned}
& U=\sqrt{\left(L-\delta_{c}+\Delta_{c}+\Delta_{s}\right)^{2}-L^{2}} \\
& P=\frac{U}{L-\delta_{c}+\Delta_{c}+\Delta_{s}} T_{s}
\end{aligned}
$$


where $\Delta_{s}$ and $\Delta_{c}$ correspond to the extension of the reinforcement and the shortening of the concrete, both along the thermally curved reference line; $T_{s}$ is the axial tensile force in the bars at the crack location; and $\delta_{c}$ is axial shortening of the concrete. The formulations for these terms are found in [9], where $\Delta_{s}$ and $\Delta_{c}$ are determined by integrating the strains along the bar, taking due account of the two regions, while $\delta_{c}$ is found similarly to $\Delta_{c}$ but accounting for the second-order thermal curvature effects. The force applied to the reinforcement is increased incrementally until the ultimate stress or strain is attained. At this point, the solutions of Eq.'s (1) and (2) determine the values of deflection and load corresponding to failure.

\subsection{Comparative assessment}

This section employs the simplified analytical approach to examine the results from the six strip specimens; the failure displacements obtained from the model, $U_{f, p r e d}$, are given in Table 1 . While these tests were limited to ambient conditions, this is believed to be a significant step and an essential precursor to the validation of the model for fire. The comparisons between the experimental and analytical responses for tests S1-S3 are depicted in Fig. 10, where the bold lines correspond to the analytical predictions. It is important to note that the load depicted in this figure is the total applied load, i.e. $2 P$ using equation (2) for the analytical prediction. It is shown that with an accurate representation of the material and geometric parameters, good agreement is achieved. The last point of each analytical curve corresponds to the attainment of ultimate strain in the reinforcement and hence indicates failure. In all experiments, the failure displacement was defined as being that at which the first reinforcement bar failed; this was accompanied by a drop in load as well as a loud and distinctive noise. These members developed a single crack and therefore, the model correctly predicts that all three will fail at the same displacement. Clearly, a realistic representation of bond strength is necessary in order to determine the failure point, and in this respect the tests are effectively used to calibrate the idealized bond strength employed in the model. In the tests with plain bars, the representative value for effective bond was found to be about $0.6-0.7 \mathrm{~N} / \mathrm{mm}^{2}$.

On the other hand, as the tests containing deformed bars failed before full tensile action developed, the analytical model does not accurately represent the 
failure load. It can however predict the displacement at which ultimate strain is reached in the steel, with reasonable accuracy. A bond strength of about 1.2$1.4 \mathrm{~N} / \mathrm{mm}^{2}$ was found to be representative for specimens S4-S6 incorporating ribbed bars, resulting in a predicted failure displacement of $58 \mathrm{~mm}$. It is shown in Table 1 that S4, S5 and S6 actually failed at displacements of 59mm, 72mm and $87 \mathrm{~mm}$ although each developed multiple, full-depth cracks. The formation of each additional crack relieves and redistributes the strain concentration in the steel, thereby delaying the attainment of ultimate strain. In these tests, a higher reinforcement ratio resulted in a greater degree of cracking and hence the corresponding failure displacement was delayed accordingly. The model assumes that a single crack will form, and hence provides a conservative failure prediction in the cases where multiple cracks appear. The bond strength considered for S4S6 therefore implicitly accounts for this effect since multiple cracking occurs even in the lightly reinforced members.

In comparing the behavioral trends of the specimens containing ribbed bars versus those with plain reinforcement, it is clear that both the steel constitutive properties and the bond stress-slip relationship have a direct influence on the overall failure displacement. The sensitivity of the ultimate behavior to these two parameters is illustrated in the following section.

\subsection{Sensitivity to material properties}

As noted before, apart from the evident effect of the ultimate strain of the reinforcement, the shape of the steel stress-strain relationship has a significant influence on member ductility. The shape of the steel constitutive relationship can vary significantly depending on the type and grade of reinforcement used. In particular, the strain hardening characteristics have a direct influence on the failure displacement. To illustrate this, specimen S1 is considered and the steel stress-strain relationship is varied as shown in Fig. 11 to reflect different strain hardening properties; $\mathrm{K} 1$ is the true relationship as employed in previous analysis. It should be noted that the ultimate stress and strain of the three relationships are identical.

The load-displacement responses for beams incorporating the three steel relationships are illustrated in Fig. 12. It is evident that whereas the load capacity at a given deformation is not notably different for each steel type, failure is 
significantly delayed when the material exhibits greater strain hardening properties. This is because localization of strain in the steel at the crack location is reduced, thereby increasing the deformation capacity of the member. This illustrates clearly that knowledge of the ultimate stress and strain for the steel is not sufficient to predict when failure will occur; it is imperative that the full representation of the steel constitutive relationship is depicted realistically for a proper assessment.

As expected and discussed previously, the bond strength between the steel and concrete has a direct influence on the ultimate behavior of lightly reinforced concrete members. It has been shown in the pullout tests that the development of bond stress is dependant on several parameters such as bar-type, slip length, cover distance, etc. In order to demonstrate the influence that bond has on the failure displacement for both bar types, two members are considered together with a range of values of bond strength $\left(\tau_{b}\right)$. Both members are of similar geometry to those in specimens S1 and S4 discussed previously. The values of $\tau_{b}$ varied from $0.1 \mathrm{~N} / \mathrm{mm}^{2}$ to $4 \mathrm{~N} / \mathrm{mm}^{2}$ in both cases and the influence on failure displacement is depicted in Fig. 13. Evidently, the failure displacement increases non-linearly for both bar-types as the bond strength decreases. Considering the member with plain bars, a relatively high bond stress $\left(4 \mathrm{~N} / \mathrm{mm}^{2}\right)$ causes the member to fail at an early stage whereas a much lower bond $\left(0.1 \mathrm{~N} / \mathrm{mm}^{2}\right)$ results in a substantially large failure displacement as it develops a greater slip length. This, in effect, reduces the concentration of strain in the steel and hence delays failure. This effect is also shown in the member containing deformed bars, although the failure displacements are much lower owing to the reduced ductility of the steel. In terms of structural behavior, it is inherently implied that a low bond stress can be beneficial when considering the ultimate limit state as it can directly result in a delay of failure and also a corresponding enhancement in load-carrying capacity.

\subsection{Failure prediction}

The experimental and analytical studies discussed in this paper and in earlier investigations $[9,11]$ have identified the key parameters influencing behavior. These comprise: the ultimate strain of the reinforcement $\left(\varepsilon_{u l t}\right)$, the bond stress $\left(\tau_{b}\right)$ between steel and concrete, the diameter of the bar $(d)$, the strain hardening properties of the reinforcement, which can be represented through the 
difference between the ultimate strength $\left(f_{u l t}\right)$ and proof or yield stress of steel $\left(f_{y}\right)$, the reinforcement cross-sectional area $\left(A_{s}\right)$ and the half-span of the member $(L)$. The results indicate a direct relationship between the general failure deflection $\left(U_{f}\right)$ normalized by the half-length $(L)$ and a parameter $\Psi_{u}$, which captures the combined influence of the above-noted parameters, such that:

$$
\Psi_{u}=\sqrt{\frac{A_{s}\left(f_{u l t}-f_{y}\right)}{\tau_{b} d \pi L} \varepsilon_{u l t}}
$$

The purpose of this parameter is to highlight the relative influence of various parameters on the failure deflection. To that end, Fig. 14 depicts the normalized failure deflection $\left(U_{f} / L\right)$ obtained from the tests as a function of the parameter $\Psi_{u}$. The relationship defined in Eq. (3) is based on the assumption that a single crack will occur at the mid-span of the member. Accordingly, the expression would tend to underestimate the failure deflection if multiple cracking occurs. As discussed before, this aspect of behavior was also observed in the experimental investigation in which, depending on the type of bars used and the reinforcement ratio, some members exhibited multiple cracking. This had the effect of enhancing the failure displacement. However, it is clear that a linear relationship can be derived, although further validation and investigation is required, and currently underway, with a view to establishing the fundamental relationship between $U_{f}$ and $\Psi_{u}$.

\section{Influence of elevated temperature properties}

At elevated temperature, the temperature distribution is assumed to be linear through the cross-section and constant along the length. The response is determined by the degradation of material properties - including those of steel, concrete and bond - combined with thermal expansion and curvature effects. In order to represent the behavior correctly, it is clearly important that the material response at elevated temperatures is accurately depicted. In this section, a brief discussion of the temperature-dependant material properties is presented. This is followed by an account of the tests carried out to determine the properties of steel reinforcement at elevated temperature. The analytical model is then applied using this information, to highlight the influence of key parameters on the prediction of failure displacement. 


\subsection{Material characteristics}

The simplified analytical model adopted in this study assumes that the concrete behaves in a linear-elastic manner while the bond-slip relationship is considered to be rigid-plastic. The degradation of the relevant parameters - i.e. the elastic modulus of concrete, $E_{c}$, and the bond strength, $\tau_{b}$ - can both be idealized as tri-linear reduction curves as shown in Fig. 15 based on information adopted in previous studies. [11, 12, 13, 14].

For reinforcing steel, a large amount of information is available on the effect of elevated temperature on both the strength of the material and also Young's modulus e.g. [14-16]. However, less reliable information is available on the influence of elevated temperature on ductility. Due to the direct reliance of the failure prediction on the ultimate mechanical strain of the reinforcement, a series of elevated temperature laboratory tests were conducted to provide the necessary information.

Tensile tests were carried out on both P6 and D6 reinforcement. The experiments were completed under 'steady-state' conditions; the temperature was increased at a rate of $10^{\circ} \mathrm{C} / \mathrm{min}$ to the required value where it was then maintained for 20 minutes to ensure a uniform temperature distribution. The bars were then tested in displacement-control until fracture occurred. As well as load and displacement readings, the extension in the heated part of the bar was measured. Each specimen was $1100 \mathrm{~mm}$ in length, $300 \mathrm{~mm}$ of which was heated inside the furnace. Prior to testing, marks were indicated on each bar at $30 \mathrm{~mm}$ intervals to facilitate the measurement of ultimate mechanical strain after the bar had cooled.

The stress-strain relationships at a given temperature $\theta$, are defined by four key parameters: (i) the slope in the linear-elastic range $\left(E_{s, \theta}\right)$, (ii) the proportional limit $\left(f_{p, \theta}\right)$ after which non-linear plastic behavior occurs, (iii) the ultimate stress $\left(f_{u l t, \theta}\right)$ corresponding to the maximum capacity of the bars and (iv) the ultimate mechanical strain at fracture $\left(\varepsilon_{u l t, \theta}\right)$. The yield stress, $f_{y, \theta}$, is notably absent from this list and is, in effect, replaced by $f_{p, \theta}$. While the yield strength is relatively straight-forward to establish at ambient temperature, the behavior becomes increasingly non-linear with elevated temperature, and both the strength and stiffness parameters decrease. Therefore $f_{y, \theta}$ cannot be determined without predefining yield strain criteria. This is typically selected between $0.1-0.2 \%$ in ambient conditions and $1-2 \%$ at elevated temperature, although since the elastic 
modulus is temperature-dependant, it is not necessarily appropriate to use identical yield strain criteria for all temperatures. Alternatively, the Eurocode assumes that in most cases strain hardening is negligible and that $f_{y, \theta}$ corresponds to the maximum level of stress in the bar at a temperature $\theta$.

The reduction of $E_{s, \theta}, f_{p, \theta}$ and $f_{u l t, \theta}$ with elevated temperature is shown for both P6 and D6 in Figs. 16 and 17. These values have been normalized against their equivalent values at ambient temperature to give $E_{s, \exp }, f_{p, \exp }$ and $f_{\text {ult,exp }}$, respectively, and plotted against temperature $(\theta)$. Also included in the graphs, for comparison, are the equivalent reduction factors prescribed by Eurocode 4 [16], namely $E_{S, E C 4}$ and $f_{p, E C 4}$; guidance is not provided about the reduction of $f_{u l t, \theta}$. The experimental results are in general agreement with the Eurocode curves and display similar trends, with the design codes providing slightly conservative recommendations. In terms of $f_{u l t}, \theta$, it is shown that the ribbed bar degrades more rapidly that the plain bar as the effects of cold-working are lost.

Most importantly, the ultimate mechanical strain $\left(\varepsilon_{u l t, \theta}\right)$ of each test specimen was measured following cooling, using the marks previously made on the bars. As the measurements were taken when the bars were cold, thermal expansion was not a factor. The results are plotted against temperature $(\theta)$ in Fig. 18 for both P6 and D6. Both bars displayed similar trends up until around $500^{\circ} \mathrm{C}$ as the ultimate strain approximately doubled within this range, increasing from 0.24 to 0.5 for the plain bars and from 0.04 to 0.09 in the deformed reinforcement. At higher temperatures, $\varepsilon_{u l t}$ of the deformed reinforcement increased significantly reaching 0.37 at $700^{\circ} \mathrm{C}$, representing an increase of $825 \%$ from the ambient value. This was not replicated in the plain reinforcement which had an ultimate strain of 0.53 at $700^{\circ} \mathrm{C}$ corresponding to a $121 \%$ increase from the ambient value. This disparity is attributed to the different manufacturing processes used for the two bar-types. It is noteworthy that, owing to the rate of heating applied, this assessment is not affected by creep strains, which can be significant in other situations. It has been shown that within a realistic range of heating rates representative of real fires, i.e. between $5^{\circ} \mathrm{C} / \mathrm{min}$ for a member with heavy insulation to $50^{\circ} \mathrm{C} / \mathrm{min}$ for a non-insulated member [17], the development of creep strain is insignificant 


\subsection{Analytical modeling}

Using the information discussed in the previous section, the simplified analytical model can be applied to assess the effect of elevated temperature on the failure displacement. Two members containing different bar-types are considered herein, and the failure displacements at various temperatures are illustrated in Fig. 19. The members are assumed to have identical geometrical and material characteristics as S1 and S4 from the ambient experimental programme. In both cases, the member ductility is shown to increase with temperature until approximately $500-600^{\circ} \mathrm{C}$ and hence failure is delayed within this range. The failure of each specimen depends directly on the combination of its thermal expansion characteristics together with the variation in the relevant material properties. It is seen that for the particular properties of the materials employed in these analyses, as the temperature approaches $700^{\circ} \mathrm{C}$, the failure deflection reduces again.

\subsection{Prediction of failure displacement}

The parameters given in Eq. (3) can also be used to develop a simple equation to predict the failure displacement at a particular temperature. This equation is more readily applicable to design applications, in comparison with aforementioned simplified analytical model. For a prescribed reinforcement temperature, $\theta$, the failure displacement $\left(U_{f, c a l c}\right)$ is determined from from [11]:

$$
U_{f, \text { calc }}=\sqrt{2 L\left(\frac{A_{s}\left(f_{u l t, \theta}-f_{p, \theta}\right)}{3 \tau_{b}} \varepsilon_{u l t, \theta}+\alpha \theta L-\frac{(\alpha \nabla \theta)^{2} L^{3}}{24}\right)}
$$

in which $U_{f, c a l c}$ is the calculated failure displacement and $\nabla \theta$ is temperature gradient in the cross-section; $\tau_{b}, f_{u l t, \theta}, f_{p, \theta}$ and $\varepsilon_{u l t, \theta}$ are the temperature-dependent material properties as previously defined, and the coefficient of thermal expansion $\alpha$ can be conservatively considered as the lower of $\alpha_{c}$ and $\alpha_{s}$ of the concrete and steel, if they differ within normal ranges. In addition to the key material parameters discussed before, Eq. (4) indicates that the effect of elevated temperature on the failure displacement is dependant on the temperature-related material properties as well as the thermal expansion and thermal gradient. 
Fig. 20 illustrates the agreement between $U_{f, c a l c}$ and $U_{f, p r e d}$, which are determined by applying Eq. (4) and the simplified analytical model respectively, when a range of temperatures is applied to two specimens with similar properties to S1 and S4 from the experimental programme. The temperature-dependant material properties are adopted from the relevant elevated temperature tensile tests and a linear temperature gradient is assumed through the cross-section. The coefficient of thermal expansion is assumed to be lower for the concrete and to have a value of $8 \times 10^{-6}$. Clearly, an excellent correlation is obtained, with both methods providing very similar failure displacements in most cases. Subject to further experimental validation under more realistic elevated temperature conditions, relationships of this form can be used as a basis for implementing appropriate failure criteria in analytical and design procedures.

A relationship can also be derived to represent the concentration of mechanical strain in the steel at the crack location, defined as the ratio of the ultimate strain $\left(\varepsilon_{u l t, \theta}\right)$ to the average strain $\left(\varepsilon_{a v, \theta}\right)$ over the half-span $(L)$ to the using similar terms to those employed in Eq. (4) [11]. The average strain in the reinforcement over a distance $L$, at a given temperature $\theta$, is given by:

$$
\varepsilon_{a v, \theta}=\frac{\Delta_{s}}{L}
$$

where $\Delta_{S}$ is the extension of the reinforcement over the member half-length, $L$. The concentration of mechanical strain in the steel at the crack location can be represented as [11]:

$$
\frac{\varepsilon_{u l t, \theta}}{\varepsilon_{a v, \theta}}=\frac{3 \tau_{b} L}{A_{s}\left(f_{u l t, \theta}-f_{p, \theta}\right)}
$$

The variation in this property (normalized to that at ambient) with temperature is illustrated in Fig. 21, where specimens with identical properties to S1 and S4 (from the ambient testing study) are assessed. For the member reinforced with plain bars, the concentration remains largely constant until about $500^{\circ} \mathrm{C}$ after which it noticeably increases. Conversely, the concentration in the element with ribbed reinforcement actually decreases gradually until about $500^{\circ} \mathrm{C}$ before this trend reverses and the concentration increases. It is worth noting that $\varepsilon_{u l t, \theta} / \varepsilon_{a v, \theta}$ has a value of 13.5 and 8.9 for the ribbed and plain bars respectively at ambient temperature This indicates that, as expected, a greater degree of strain 
concentration occurs for the ribbed bar owing to its higher bond strength. However, the variation in the strain concentration at elevated temperature, clearly depends directly on the variation of $\tau_{b}, f_{p, \theta}$ and $f_{u l t, \theta}$ with temperature, hence emphasizing the importance of accurately representing these properties in the analysis.

\section{Concluding remarks}

This paper dealt with the ultimate behavior of idealized composite slab elements which resemble lightly reinforced concrete members under simulated fire conditions due to the early loss of the steel deck. Particular attention was given to the failure state associated with rupture of the reinforcement. A fundamental analytical approach, which can be used to predict the failure displacement under both ambient and elevated temperature conditions, was outlined. In order to validate and calibrate the suggested analytical procedures and expressions, ambient tests on isolated axially-restrained reinforced concrete elements were presented and discussed. The tests illustrated the influence of the type and ratio of reinforcement on the ductility of the members. Importantly, it was shown that despite the lower yield strength of plain bars, in comparison with ribbed bars, they can sustain higher loads through tensile catenary action owing to their relatively low bond strength. It was also shown that, with an appropriate depiction of characteristic bond and other material properties, the failure point can be predicted with reasonable accuracy. Additionally, the paper presented a complementary experimental assessment which was carried out to ascertain the properties of the reinforcement employed in this study, particularly in terms of their ultimate mechanical strain, at temperature levels which may be reached in actual fire conditions. The resulting properties were used, in conjunction with other existing information, to illustrate the influence of temperature effects on the failure displacement, pending further validation by actual fire tests on structural members and assemblages. Overall, this paper demonstrates the important role played by a number of material properties, such as bond strength and reinforcement stress-strain characteristics, at ambient and elevated temperature, on failure. 
The support provided by the Engineering and Physical Sciences Research Council (EPSRC) in the UK for the work described in this paper is gratefully acknowledged. The authors would also like to thank the technical staff of the structures laboratories at Imperial College London, particularly Mr.

Trevor Stickland, for their assistance with the experimental work.

\section{Notation}

The following symbols are used in this paper:

$A_{s} \quad$ area of steel reinforcement;

d reinforcement bar diameter;

$E_{c} \quad$ elastic Young's modulus of concrete;

$E_{S} \quad$ elastic Young's modulus of steel at ambient temperature;

$E_{S, E C 4}$ elastic Young's modulus of steel at elevated temperature as specified in Eurocode 4;

$E_{s, \exp } \quad$ normalized values for elastic Young's modulus of steel at elevated temperature;

$E_{s, \theta} \quad$ elastic Young's modulus of steel at elevated temperature $\theta$;

$F_{f, t e s t}$ total experimental applied load at failure;

$f_{p, \theta} \quad$ characteristic proportional limit steel reinforcement at elevated temperature $\theta$;

$f_{p, \exp } \quad$ normalized values for characteristic proportional limit steel reinforcement at elevated temperature;

$f_{p, E C 4} \quad$ characteristic proportional limit steel reinforcement at elevated temperature, as specified in Eurocode 4;

$f_{u l t} \quad$ characteristic ultimate strength of the steel reinforcement at ambient temperature;

$f_{\text {ult,exp }}$ normalized values for characteristic ultimate strength of steel reinforcement at elevated temperature;

$f_{u l t, \theta} \quad$ characteristic ultimate strength of the steel reinforcement at elevated temperature $\theta$;

$f_{y} \quad$ characteristic yield strength of the steel reinforcement at ambient temperature;

$f_{y, \theta} \quad$ characteristic yield strength of the steel reinforcement at elevated temperature $\theta$;

$h_{c} \quad$ assumed distance of contact point from level of reinforcement;

$L \quad$ half span of member;

$P \quad$ general term for half the member mid-span load;

$T_{S} \quad$ tensile force in reinforcement at crack location;

$U$ general term for vertical displacement;

$U_{f} \quad$ general term for vertical displacement at failure;

$U_{f, \text { calc }}$ calculated term for vertical displacement at failure, using reduced expression;

$U_{f, p r e d}$ predicted term for vertical displacement at failure, using the simplified analytical approach;

$U_{f, t e s t}$ experimental vertical displacement at failure;

$\alpha_{c} \quad$ coefficient of thermal expansion for concrete;

$\alpha_{s} \quad$ coefficient of thermal expansion for steel;

$\delta_{c 0} \quad$ axial shortening of the concrete;

$\Delta_{c} \quad$ shortening of concrete along thermally curved reference line; 
$\Delta_{s} \quad$ extension of steel reinforcement along thermally curved reference line;

$\varepsilon_{u l t} \quad$ ultimate strain of steel at ambient temperature;

$\varepsilon_{u l t, \theta} \quad$ ultimate strain of steel at elevated temperature $\theta$;

$\theta \quad$ temperature of steel reinforcement;

$\rho$ reinforcement ratio;

$\tau_{b} \quad$ bond stress;

$\Psi_{u} \quad$ parameter related to normalized failure deflection at ambient; and

$\nabla \theta \quad$ thermal gradient over cross section.

Reference:

[1] Wang, Y.C., Lennon, T., and Moore, D.B. (1995), The behaviour of steel frames subject to fire, Journal of Constructional Steel Research, 35:291-322

[2] Huang, Z., Burgess, I. W. and Plank, R. J. (1999), Nonlinear analysis of reinforced concrete slabs subjected to fire, American Concrete Institute Structural Journal 96(1):127-135

[3] Bailey, C.G. and Moore, D.B. (2000), The structural behavior of steel frames with composite floor slabs subject to fire. Part 1: Theory, The Structural Engineer, 78(11):19-27

[4] Bailey, C.G. and Moore, D.B. (2000), The structural behavior of steel frames with composite floor slabs subject to fire. Part 2: Design, The Structural Engineer, 78(11):28-33

[5] Gillie, M., Usmani, A.S., and Rotter, J.M. (2001), A structural analysis of the first Cardington test, Journal of Constructional Steel Research, 57:581-601

[6] Elghazouli, A. Y. and Izzuddin, B. A. (2001), Analytical assessment of the structural performance of composite floors subject to compartment fires, Fire Safety Journal, 36:769-793

[7] Lim, L., Buchanan, A. and Moss, P. (2003), Experimental testing and numerical modelling of two-way concrete slabs under fire conditions, Journal of the Structural Engineering Society New Zealand, SESOC, 12-26

[8] O'Connor, M. A., and Martin, D. M. (1998). Multi-storey steel framed building subjected to subjected to fire attack. Journal of Constructional Steel Research, 46(1):Paper 169

[9] Izzuddin, B. A. and Elghazouli, A. Y. (2004), Failure of lightly reinforced concrete members under fire. I: Analytical modeling, Journal of Structural Engineering, 130(1):3-17

[10] Cashell, K.A. (2009), Failure assessment of floor slab systems under extreme loading conditions, PhD Thesis, to be submitted, Imperial College London

[11] Elghazouli, A. Y. and Izzuddin, B. A. (2004), Failure of lightly reinforced concrete members under fire. II: Parametric studies and design considerations, Journal of Structural Engineering, 130(1):18-31

[12] Morley P.D. and Royles R. (1983), Response of the bond in reinforced concrete to high temperatures, Magazine of Concrete Research, 35(123):67-74

[13] Sager, H. and Rostasy, F.S. (1982), The effect of elevated temperature on the bond behavior of embedded reinforcing bars, Bond in Concrete, P. Bartos, ed., Applied Science Publishers, London, 206-216

[14] Buchanan, A.H. (2001), Structural design for fire safety, Wiley, New York

[15] Anderberg Y. (1978), Analytical fire engineering design of reinforced concrete structures based on real fire characteristics, Proceedings of the FIP, London, Part 1: 112-121. 
[16] Eurocode 4 (2005). Design of composite steel and concrete structures: Part 1.2: General rulesStructural fire design, European Committe for Standardization, Brussels. BS EN 1994-1-2.

[17] Twilt L. (1988), Strength and deformation properties of steel at elevated temperatures: Some practical implications, Fire Safety Journal, 13: 9-15. 
Table 1: Experimental details

\begin{tabular}{|c|c|c|c|c|c|c|c|c|c|c|}
\hline Test & $\begin{array}{c}\text { Length } \\
\text { (mm) }\end{array}$ & $\begin{array}{l}\text { Width } \\
\text { (mm) }\end{array}$ & $\begin{array}{l}\text { Depth } \\
(\mathrm{mm})\end{array}$ & $\begin{array}{l}\text { Bar } \\
\text { type }\end{array}$ & $\begin{array}{c}\text { Spacing } \\
\text { (mm) }\end{array}$ & $\begin{array}{c}\rho \\
(\%)\end{array}$ & $\begin{array}{c}\text { No. } \\
\text { cracks }\end{array}$ & $\begin{array}{l}F_{f, \text { test }} \\
(\mathbf{k N})\end{array}$ & $\begin{array}{l}U_{f, \text { test }} \\
(\mathbf{m m})\end{array}$ & $\begin{array}{l}U_{f, \text { pred }} \\
(\mathrm{mm})\end{array}$ \\
\hline S1 & 1500 & 600 & 60 & P6 & 200 & 0.23 & 1 & 11.8 & 172 & 170 \\
\hline S2 & 1500 & 540 & 60 & P6 & 90 & 0.52 & 1 & 24.6 & 175 & 170 \\
\hline S3 & 1500 & 520 & 60 & P6 & 40 & 1.18 & 1 & 55.2 & 180 & 170 \\
\hline S4 & 1500 & 600 & 60 & D6 & 200 & 0.23 & 2 & 4.4 & 59 & 58 \\
\hline S5 & 1500 & 540 & 60 & D6 & 90 & 0.52 & 5 & 9.4 & 72 & 58 \\
\hline S6 & 1500 & 520 & 60 & D6 & 40 & 1.18 & 9 & 25.4 & 87 & 58 \\
\hline
\end{tabular}




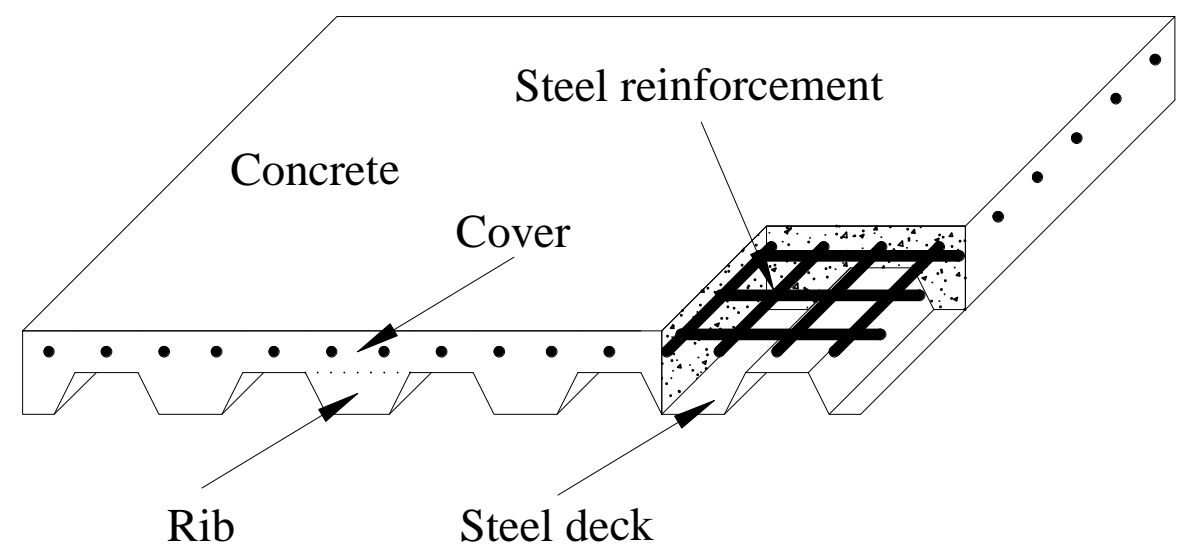

Fig. 1 - Typical configuration of composite profiled slabs

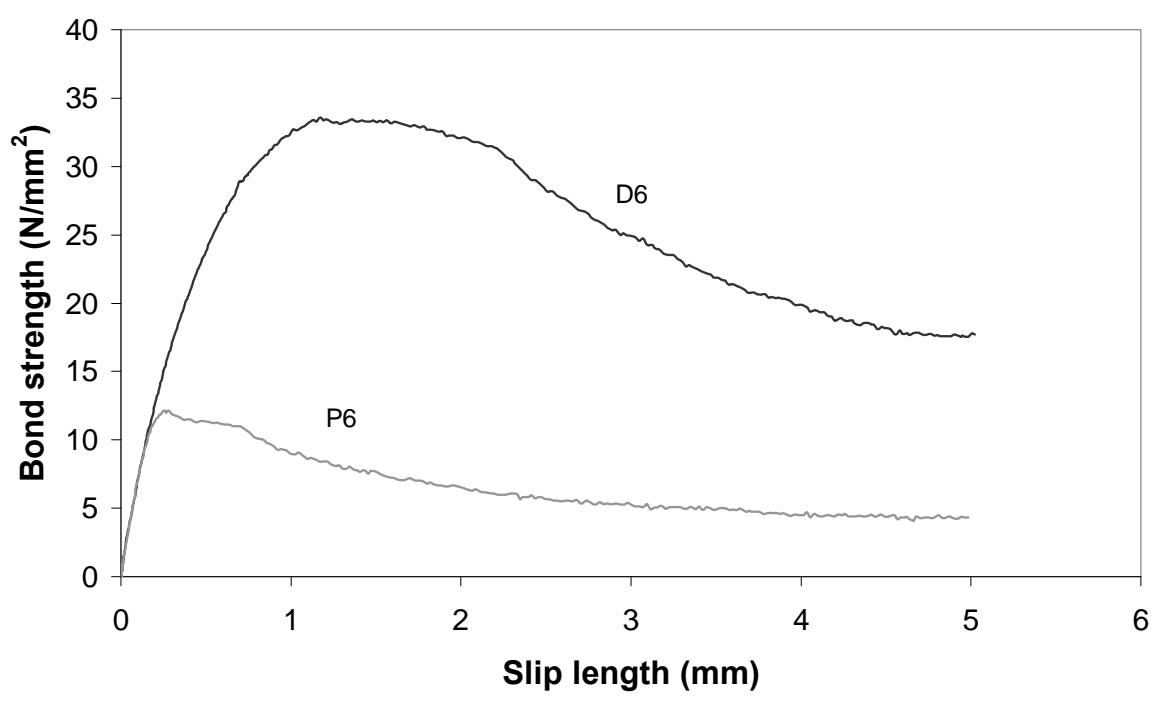

Fig. 2 - Influence of bar type on bond-slip 


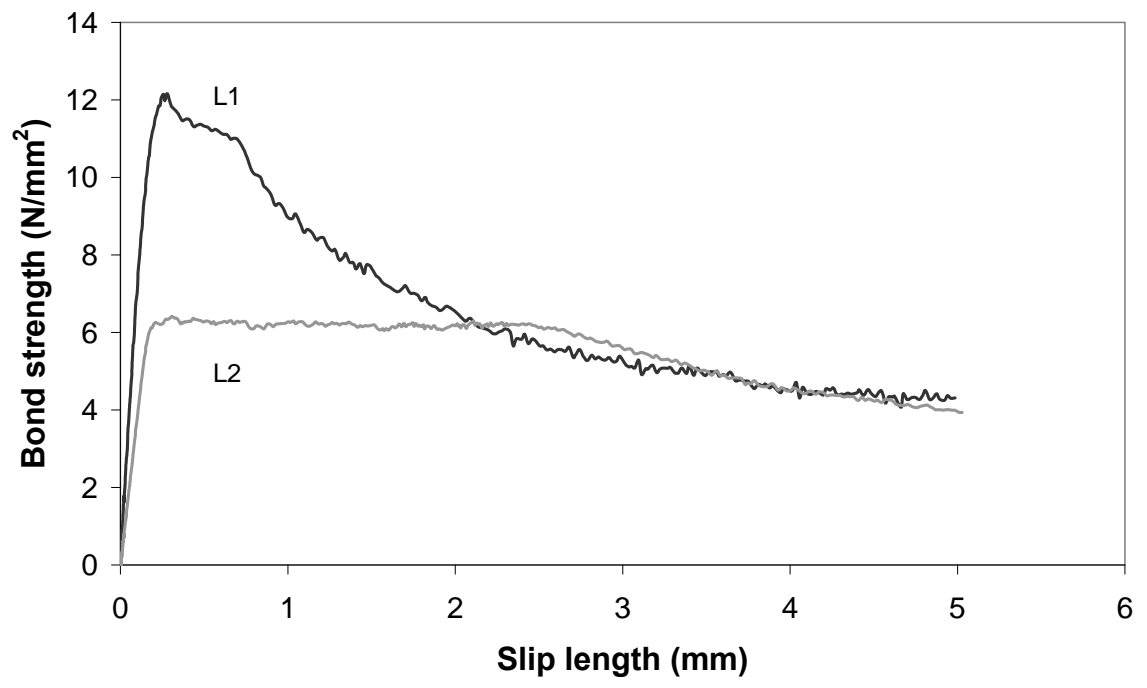

Fig. 3 - Influence of embedment length on bond-slip

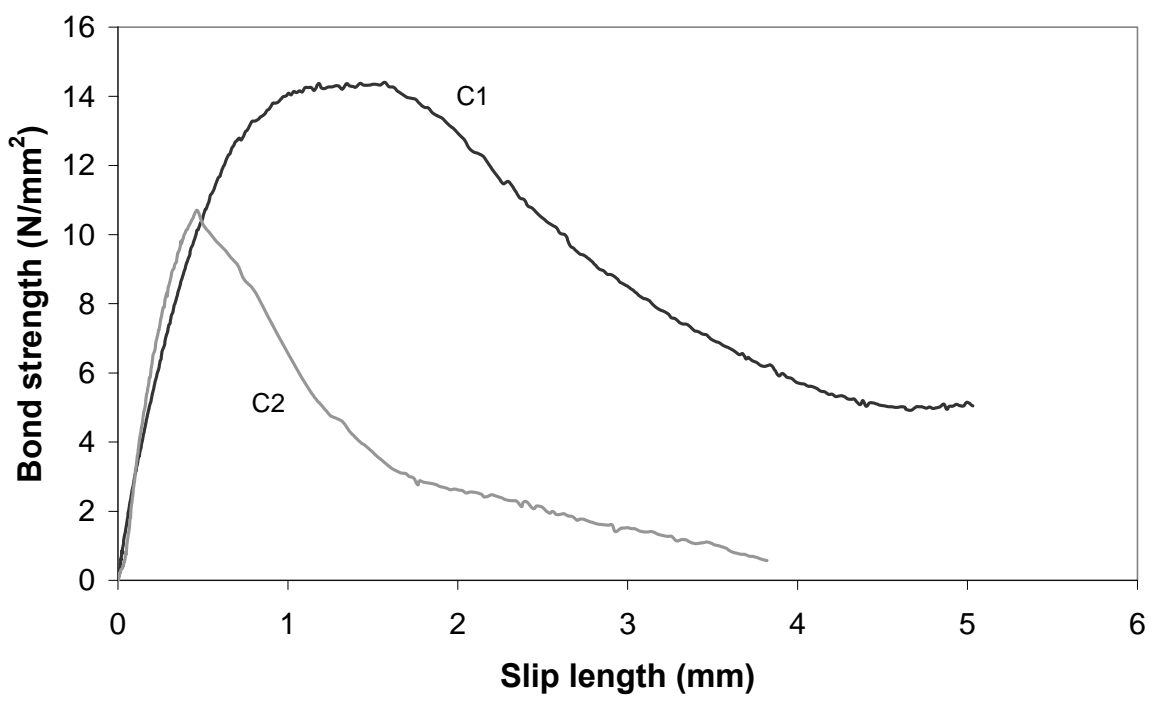

Fig. 4 - Effect of concrete cover 


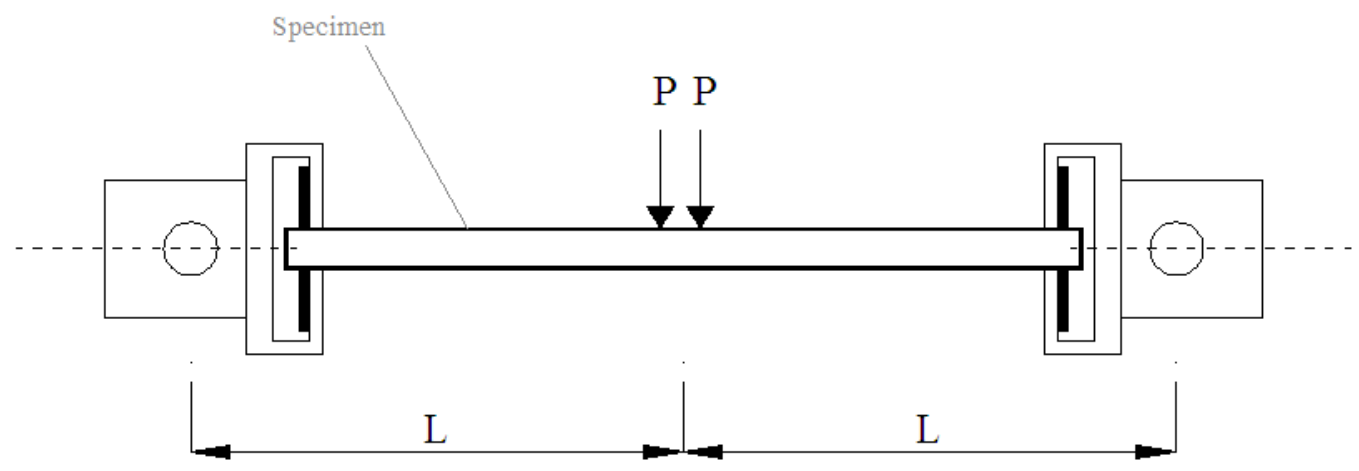

Fig. 5 - General arrangement of test rig

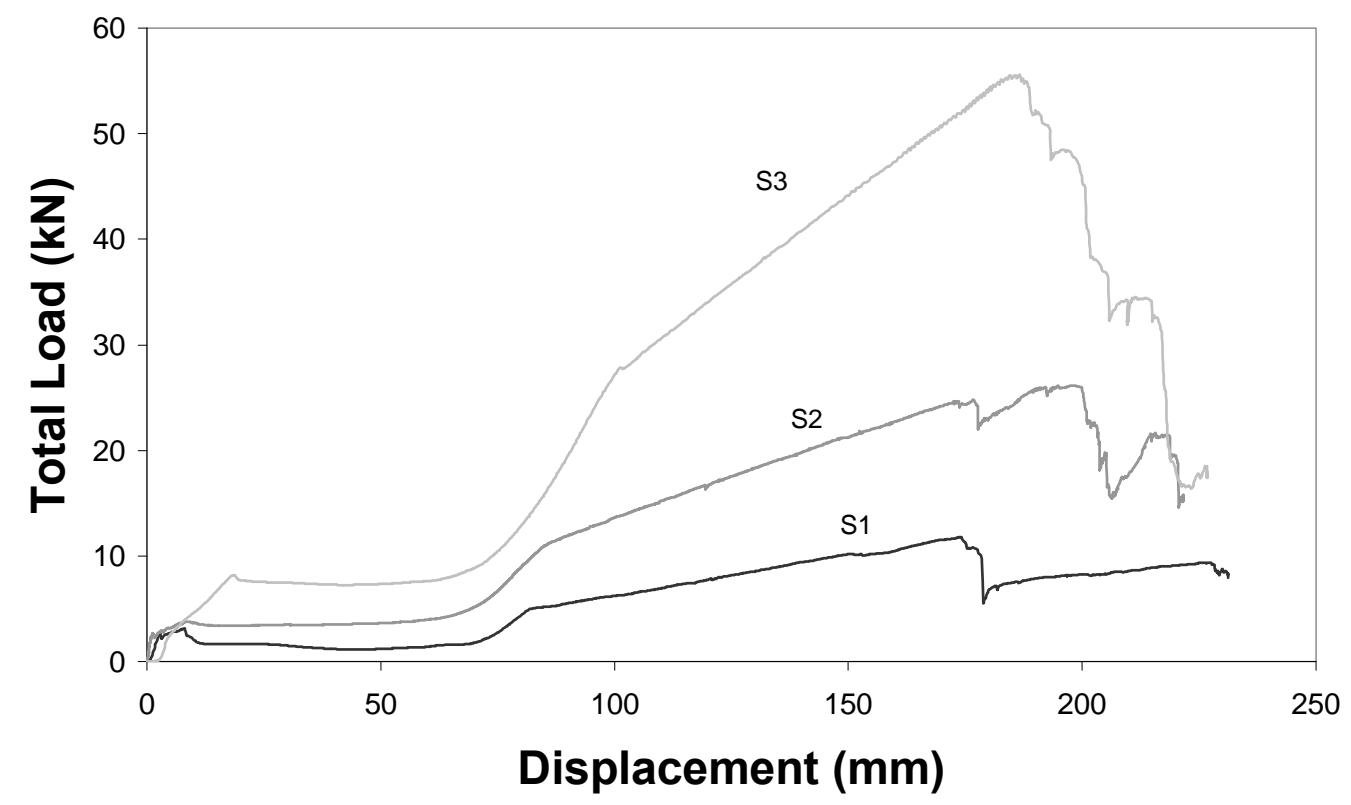

Fig. 6 - Specimens with plain bars 


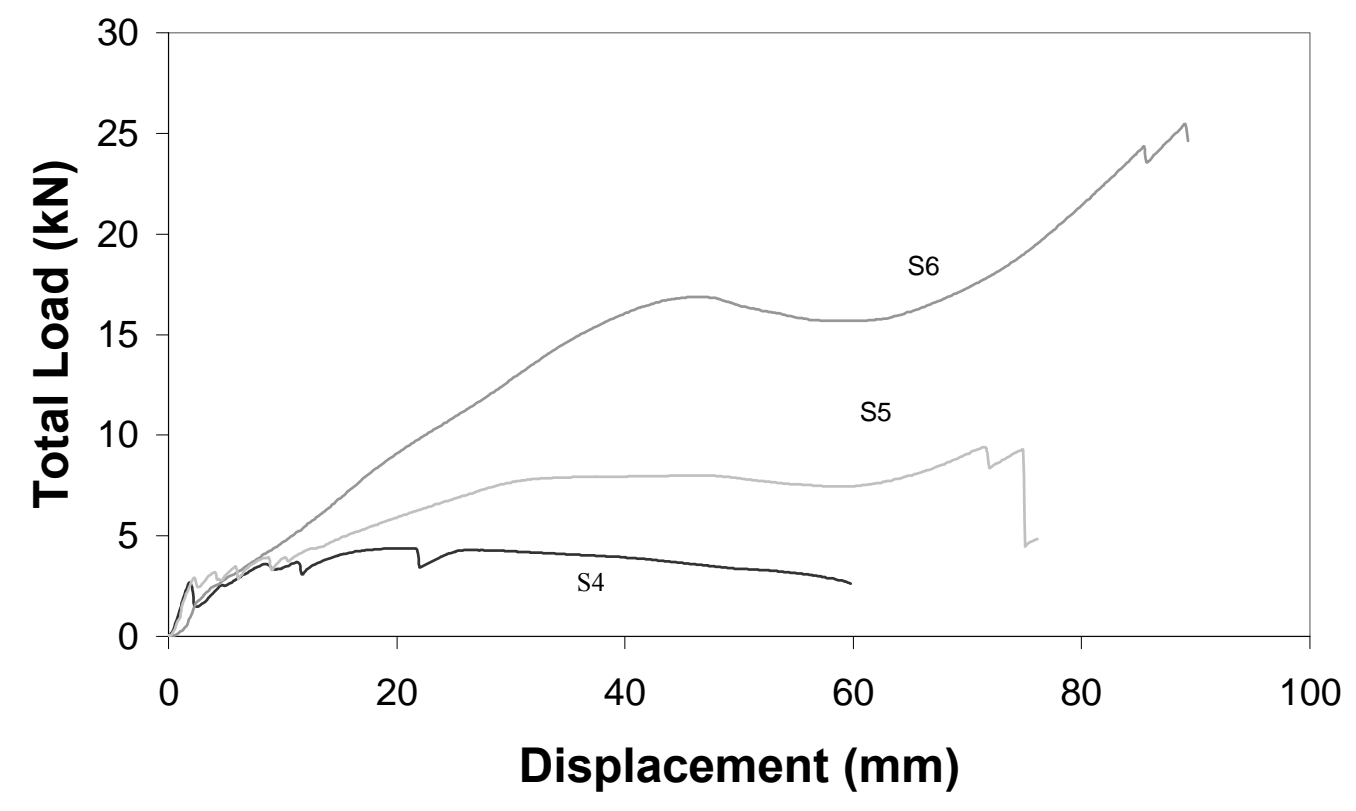

Fig. 7 - Members with deformed bars

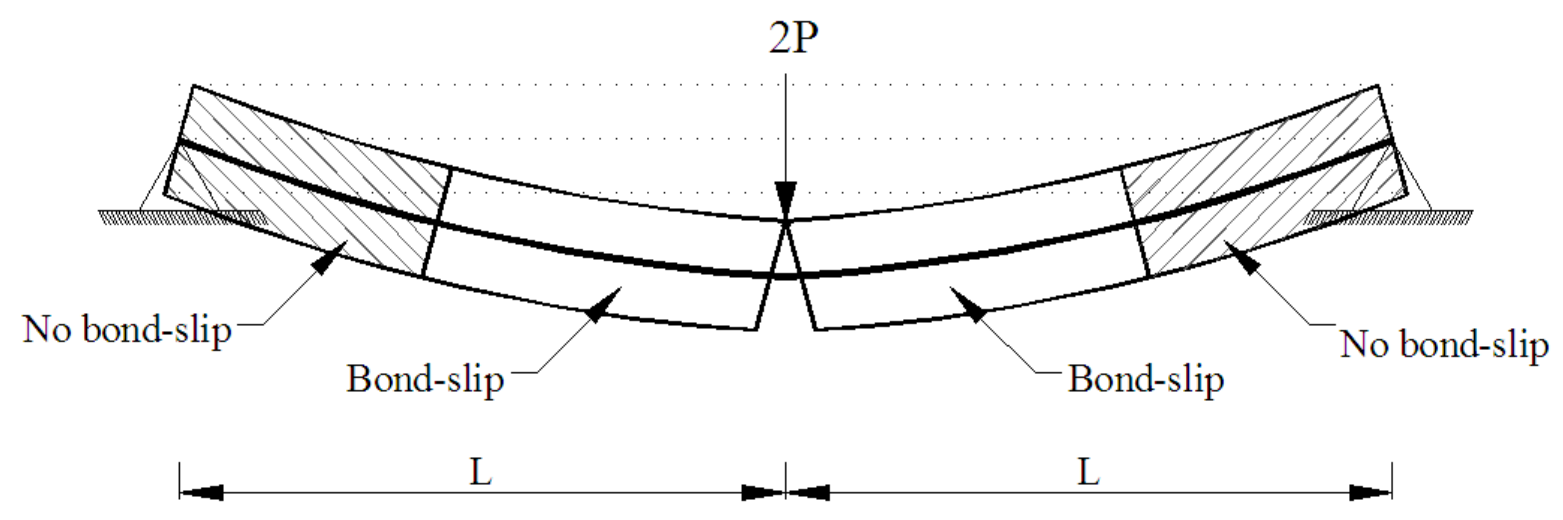

Fig. 8 - Layout of lightly reinforced member indicating bond-slip regions [9] 


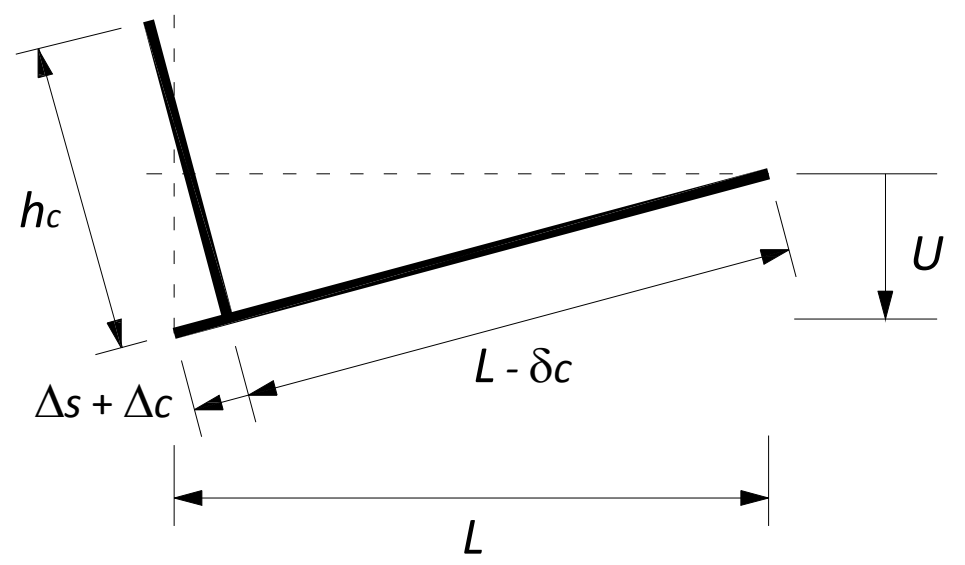

Fig. 9 - Compatibility diagram of simplified analytical model (exaggerated depth) [9]

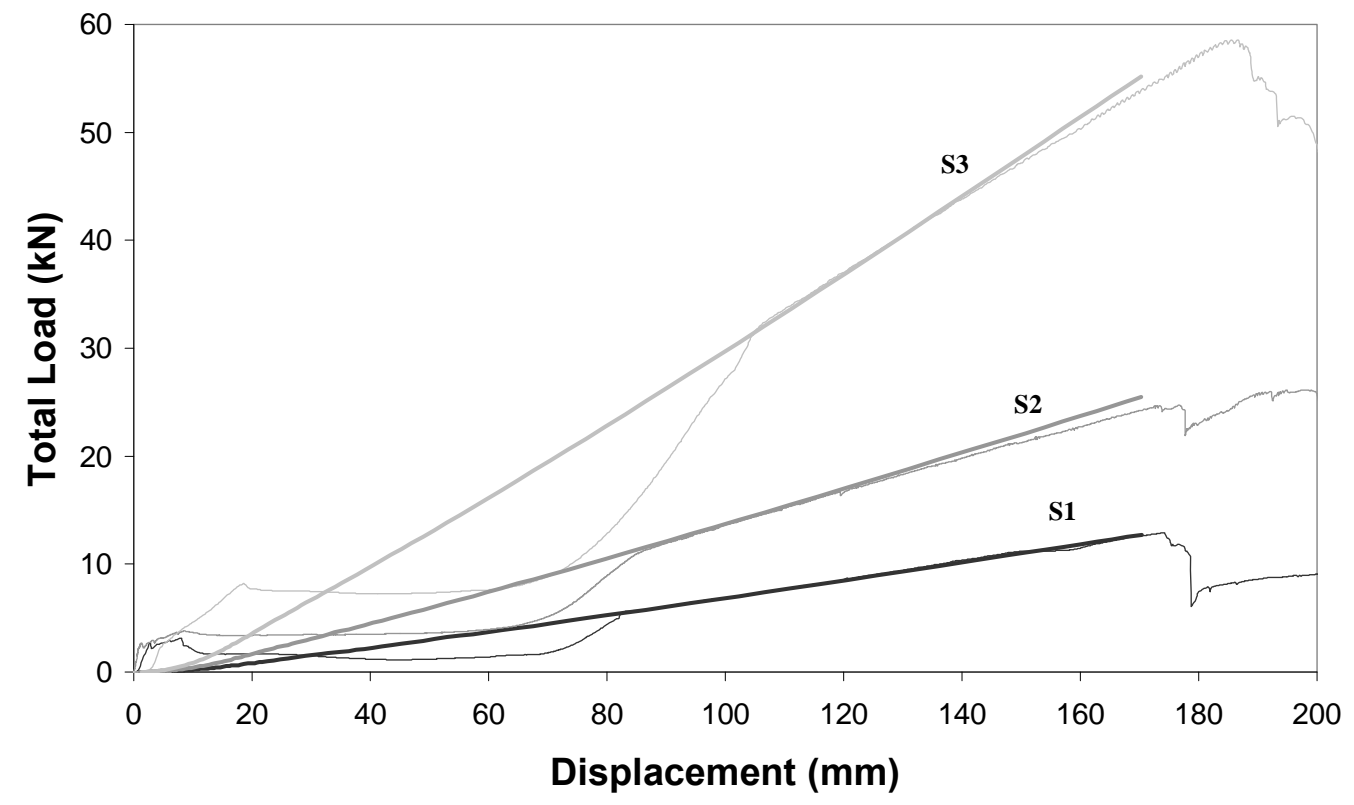

Fig. 10 - Prediction of tensile catenary response in Tests S1, S2 and S3 


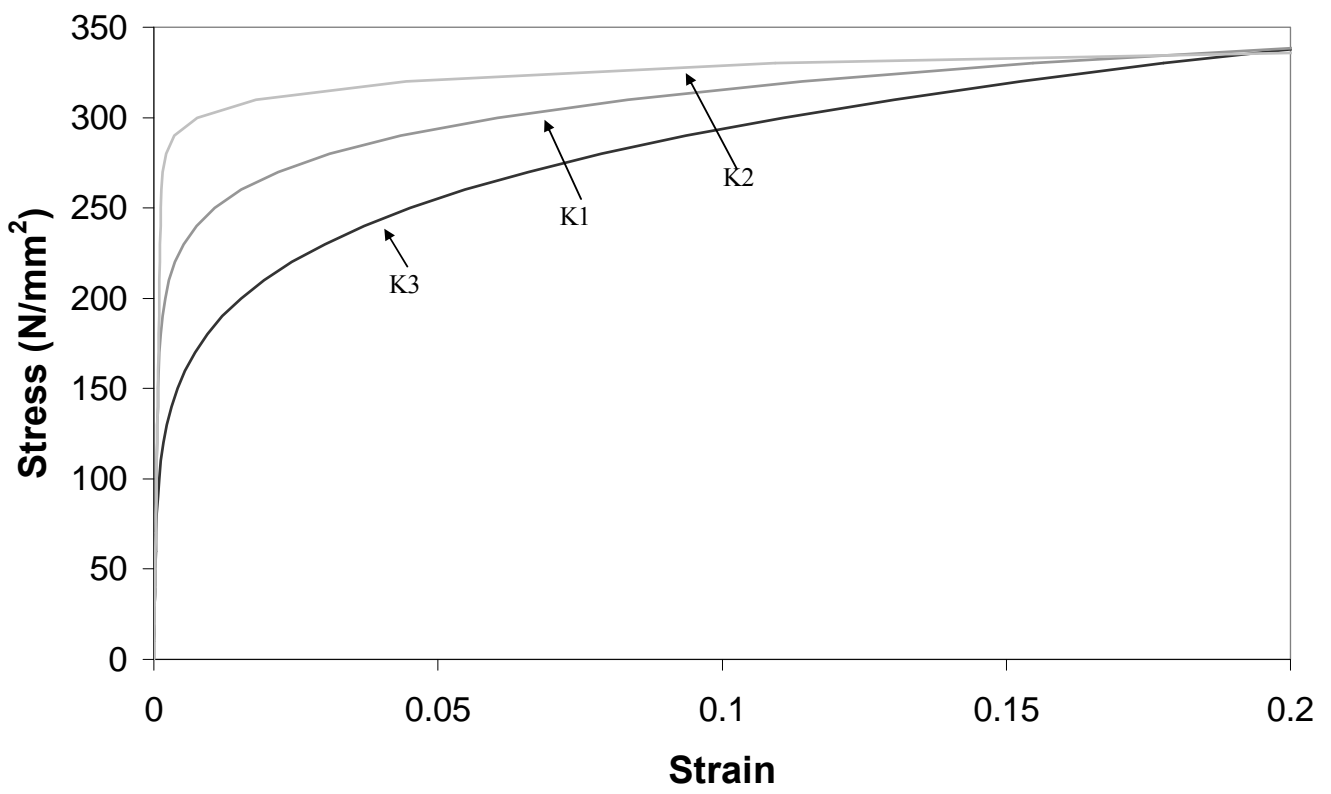

Fig. 11 - Various steel constitutive relationships

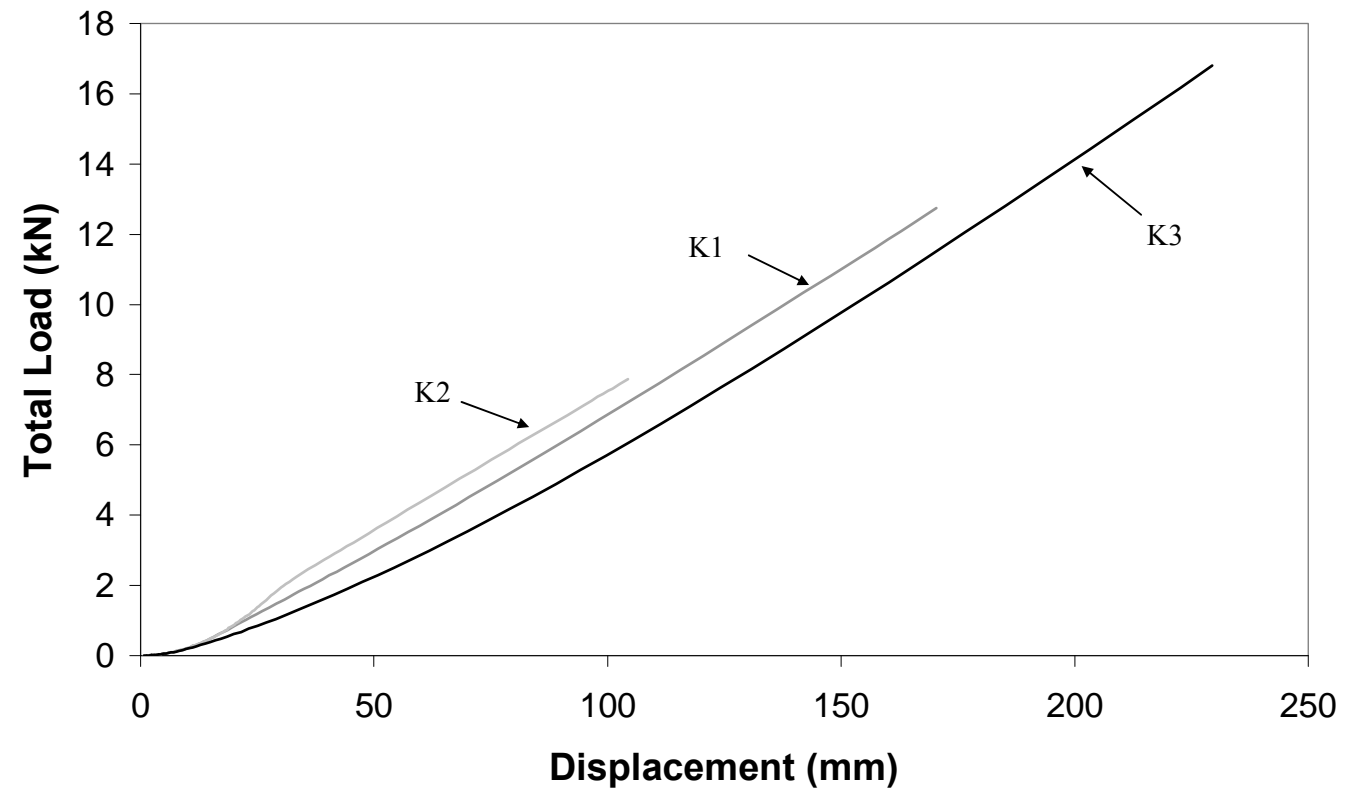

Fig. 12 - Effect of different steel constitutive relationships on failure 


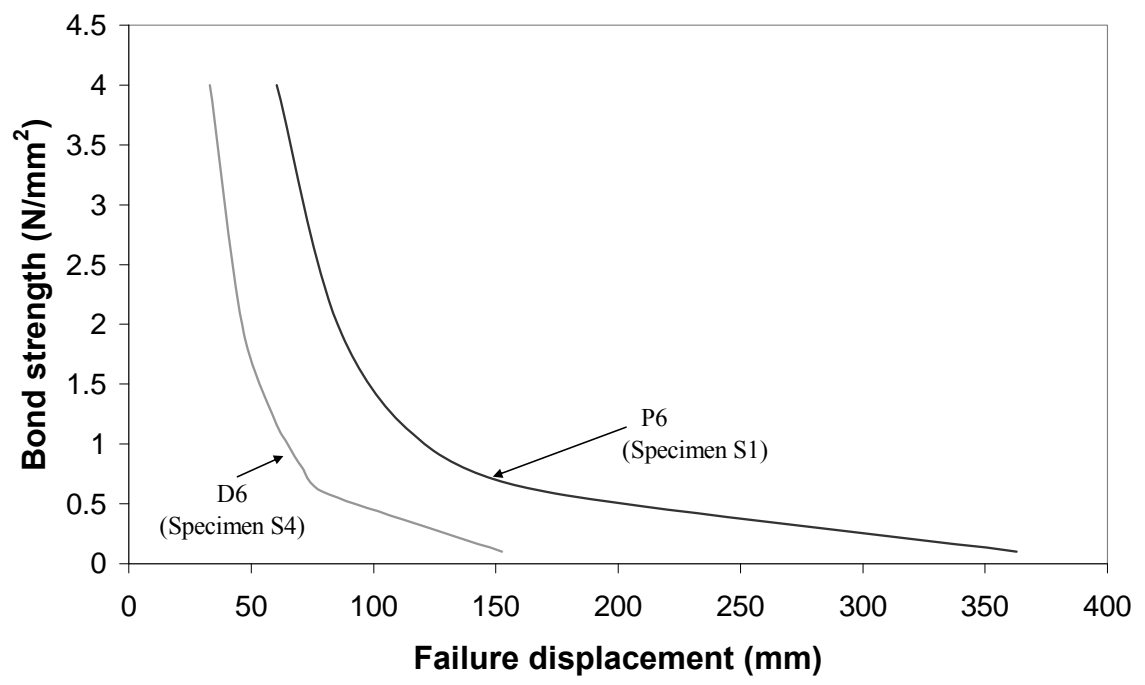

Fig. 13 - Effect of bond strength on response and failure limit

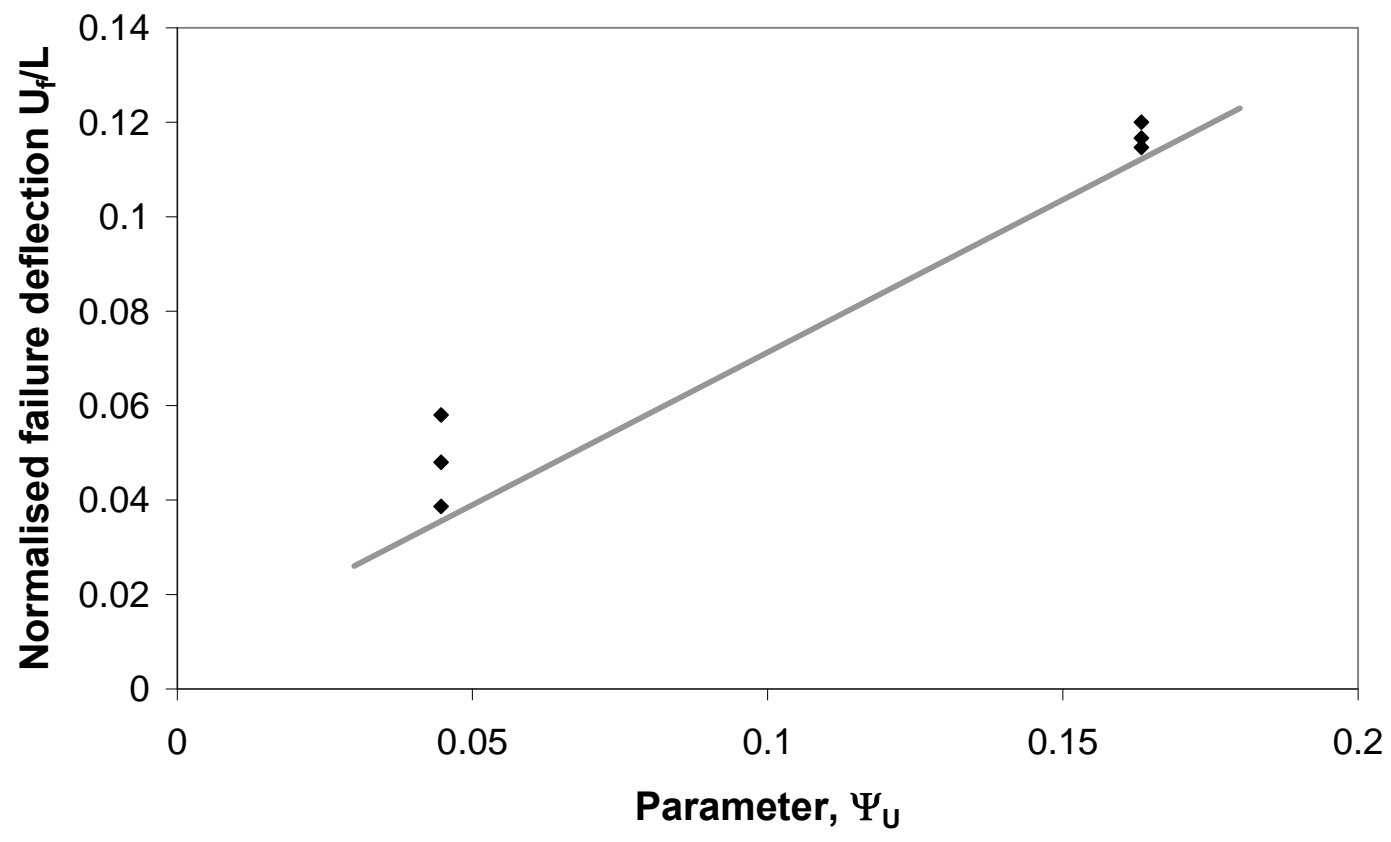

Fig. 14 - Vertical deflection at failure 


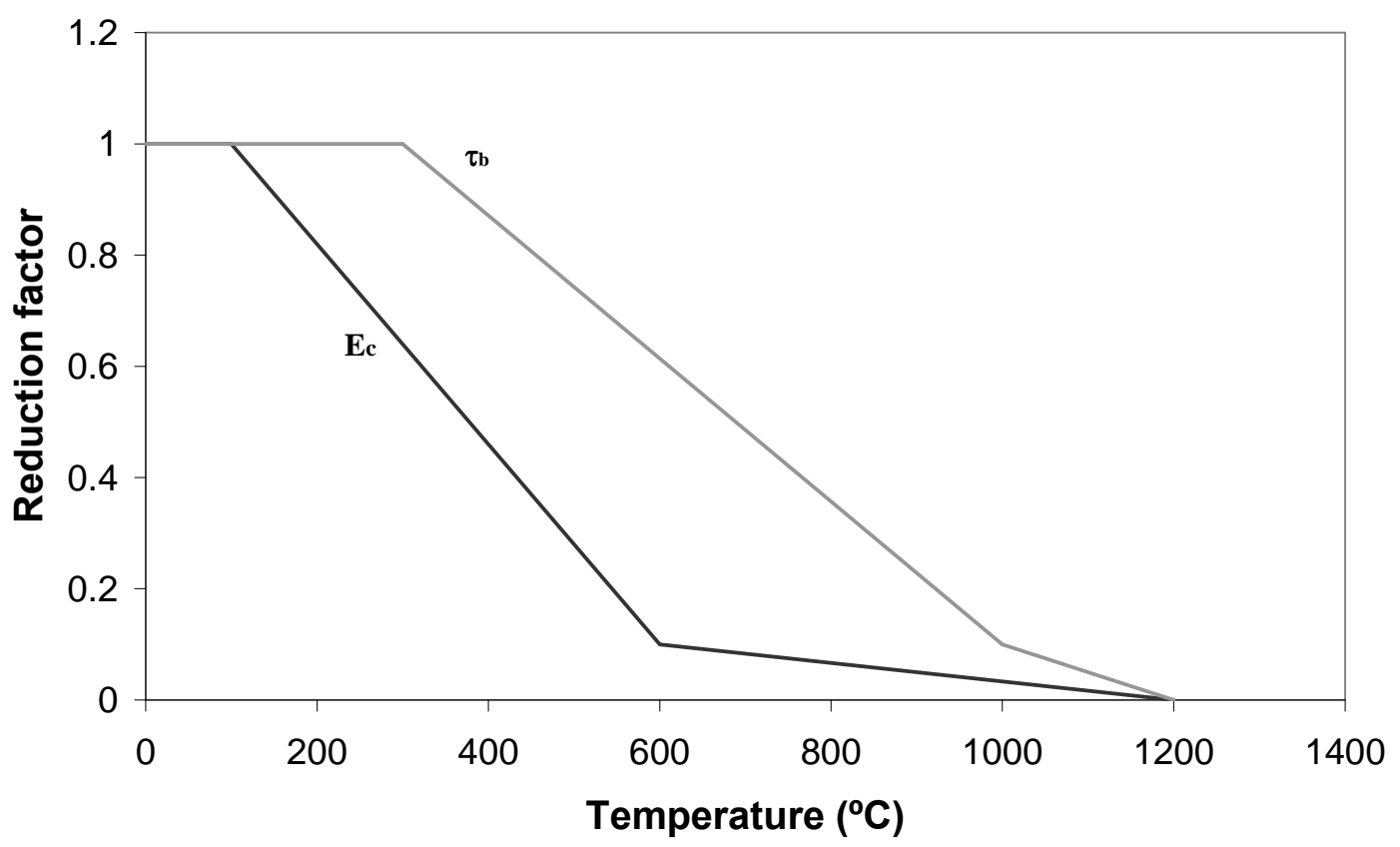

Fig. 15 - Reduction factors for $E_{c}$ and $\tau_{b}$

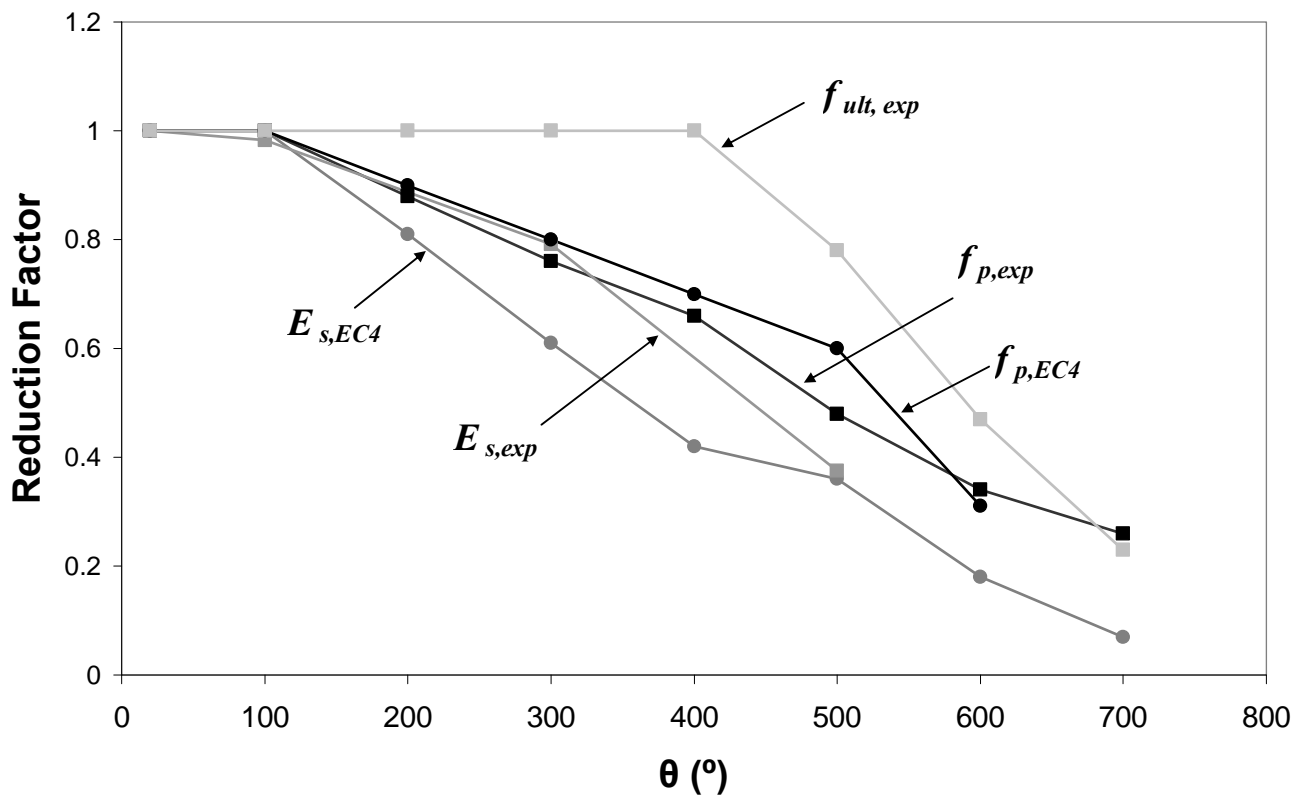

Fig. 16 - Effect of temperature on material characteristics of P6 


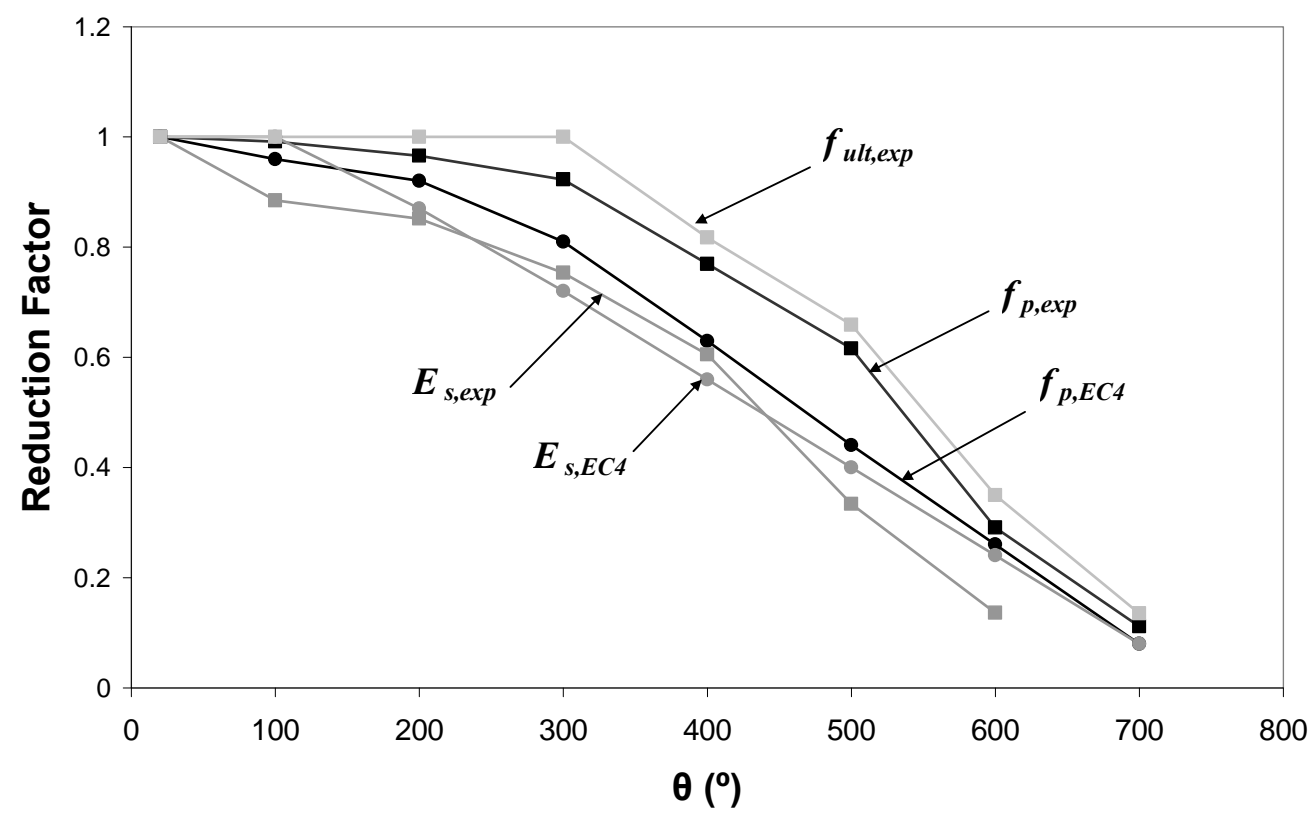

Fig. 17 - Effect of temperature on material characteristics of D6

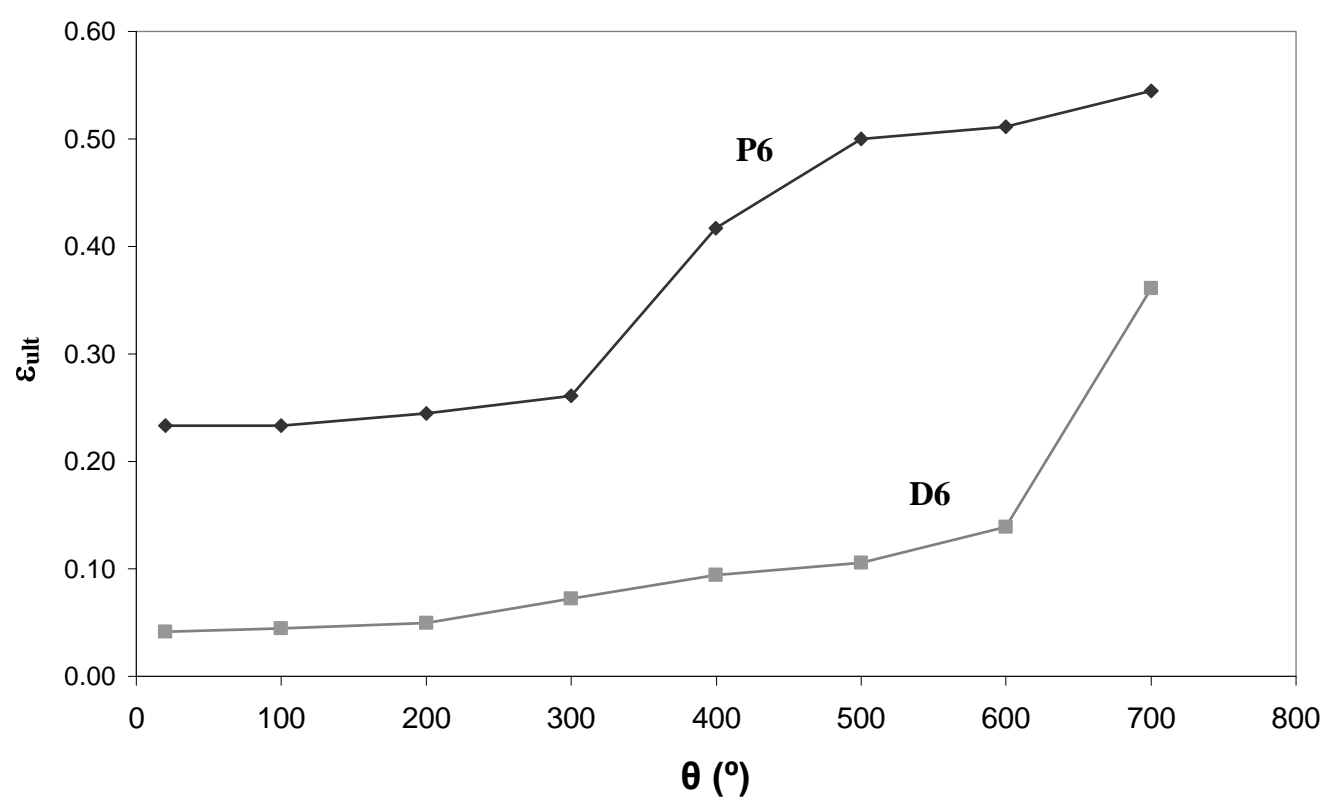

Fig. 18 - Effect of temperature on ultimate strain for both P6 and D6 


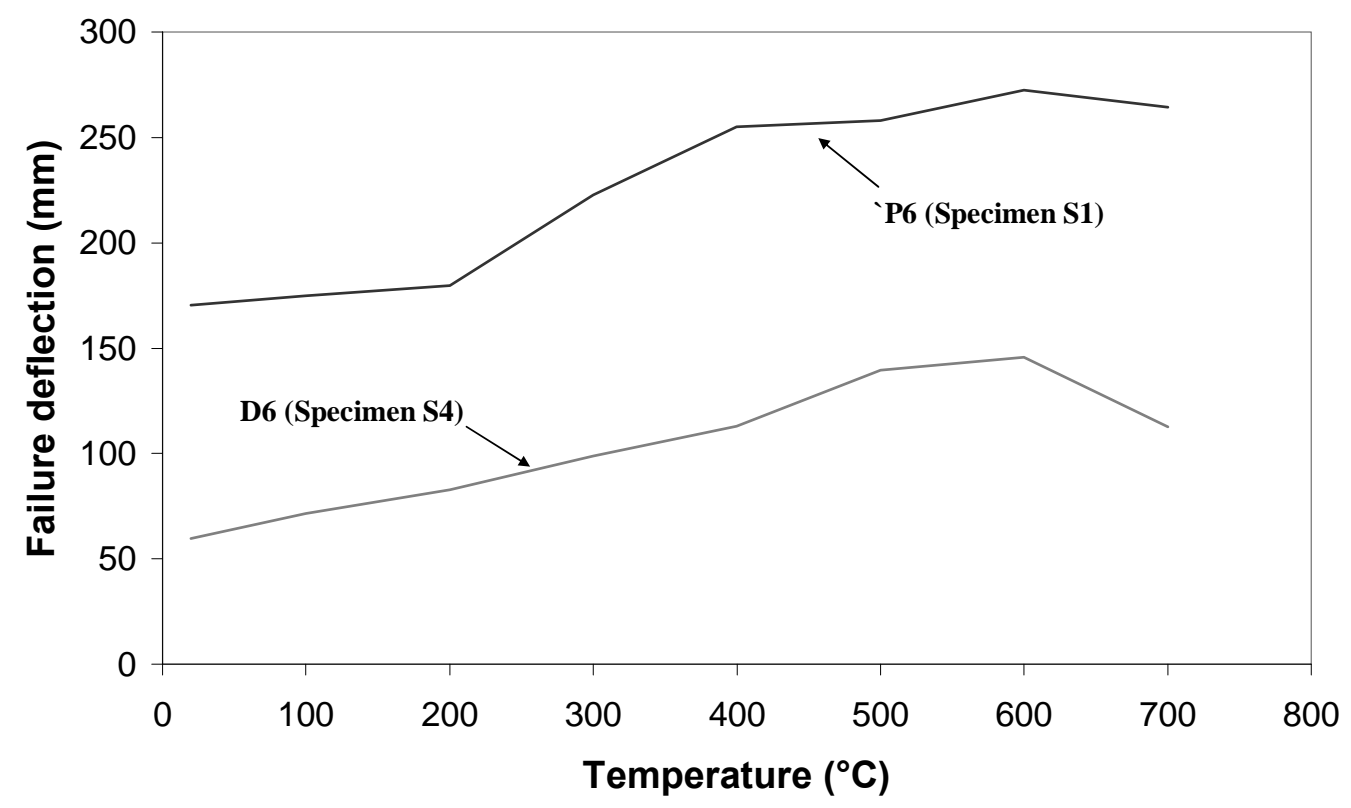

Fig. 19 - Influence of temperature on failure displacement

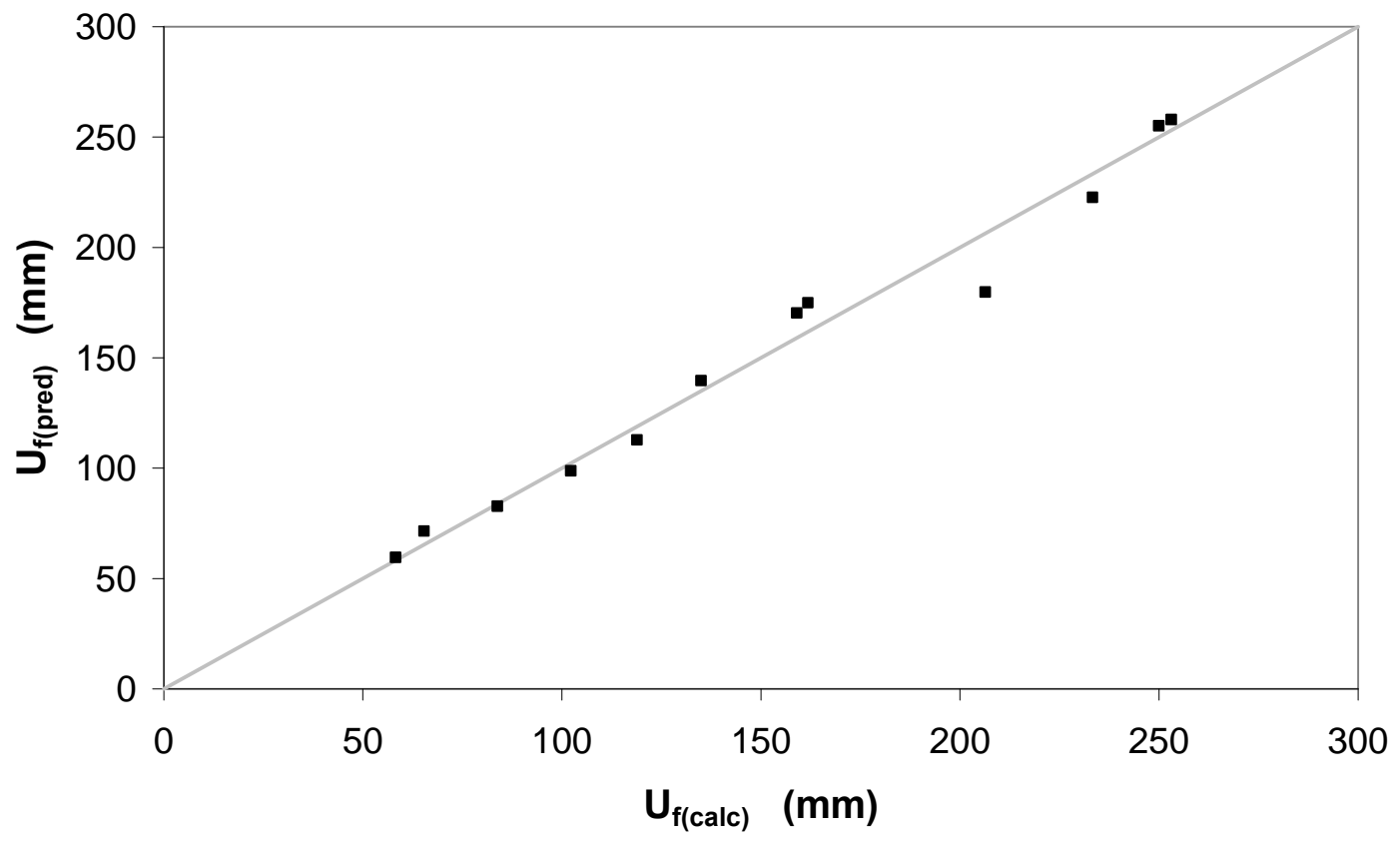

Fig. 20 - Prediction of failure displacement using the expression of Eq. (4) and the simplified analytical model 


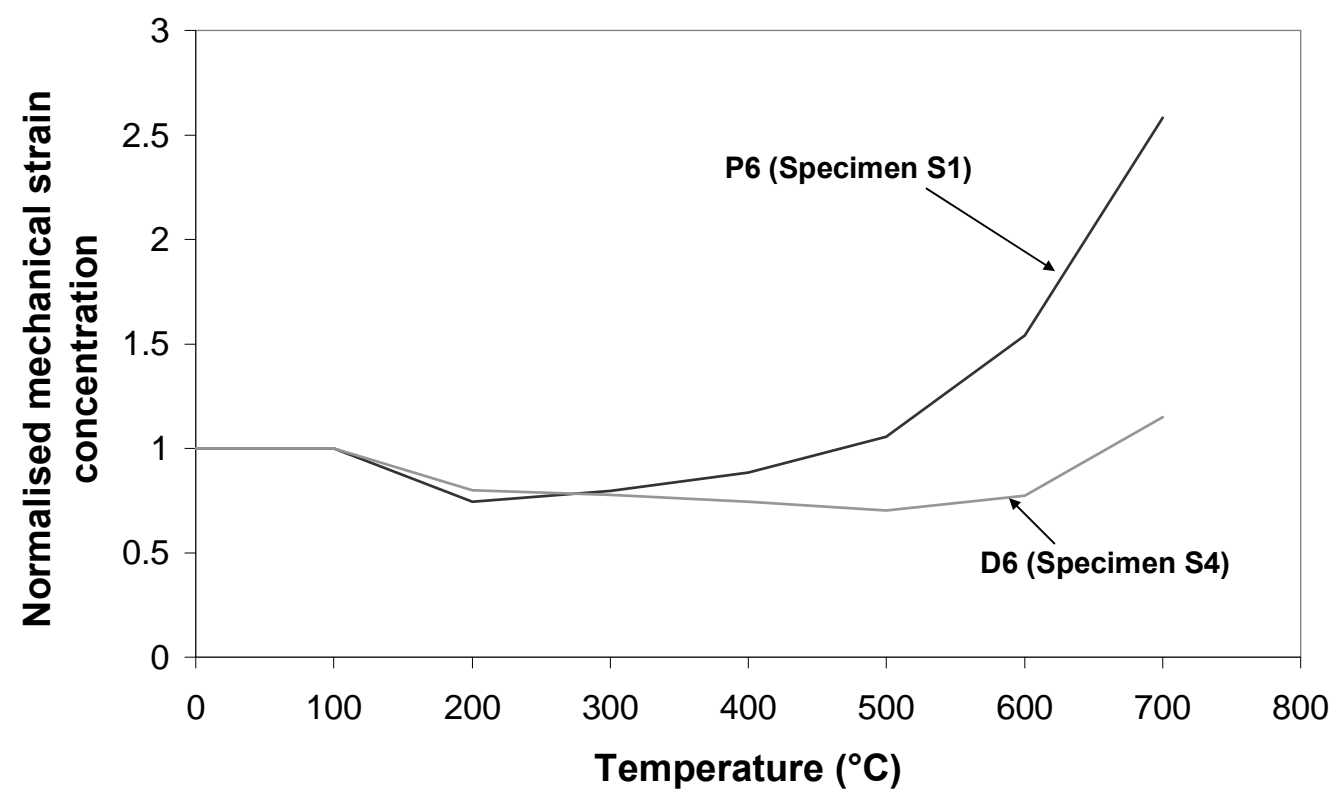

Fig. 21 - Mechanical strain concentration at elevated temperature normalized to that at ambient temperature 